\author{
Title Page
}

\title{
AN INHIBITOR OF NEURONAL EXOCYTOSIS (DD04107) DISPLAYS LONG- LASTING in vivo ACTIVITY AGAINST CHRONIC INFLAMMATORY AND NEUROPATHIC PAIN
}

Berta Ponsati, Cristina Carreño, Verdad Curto-Reyes, Belen Valenzuela, María José Duart, Wim Van Den Nest, Omar Cauli, Beatriz Beltran, Jimena Fernandez, Franco Borsini, Antonio Caprioli, Stefano Di Serio, Mario Veretchy, Ana Baamonde, Luis Menendez, Francisco Barros, Pilar de la Pena, Ricardo Borges, Vicente Felipo, Rosa Planells-Cases, Antonio Ferrer-Montiel.

BP, JF, BCN Peptides, Sant Quintí de Mediona, Spain. CC, WVDN, DiverDrugs, Gavà, Spain. VC-R, AB, LM, FB, PP, Universidad de Oviedo, Oviedo, Spain. BV, Hospital San Jaime, Torrevieja, Spain. MJD, AF-M Universidad Miguel Hernández, Elche, Spain. OC, VF, RP-C, Centro de Investigaciones Príncipe Felipe, Valencia, Spain, BB, RB, Universidad de la Laguna, Tenerife, Spain. FB, AC, SDS, MV, Sigma-Tau, Roma, Italy. 


\section{Running title page}

Running title: Anti-nociception by blocking neuronal exocytosis.

*To whom correspondence should be addressed: Prof. Antonio Ferrer-Montiel, Instituto de Biología Molecular y Celular, Universidad Miguel Hernández, Av. de la Universidad, 03202 Elche, Spain. Phone: +34966658727; fax +34966658758; email: aferrer@umh.es. URL address: http://ibmc.umh.es

Text pages: 34

Tables: $\quad 4$

Figures: $\quad 8$

References: 40

Abstract: 215 words

Introduction: 580 words

Discussion: 1230 words

Abbreviations: TRPV1, transient receptor potential vanilloid-I; SNAP-25, synaptosomal protein of $25 \mathrm{kDa}$ molecular weight; SNARE, Soluble N-ethylmaleimidesensitive factor Attachment Protein receptor; CFA, Complete Freund Adjuvant; STZ, streptozotocin; CGRP, calcitonin gene related peptide; BoNTA, botulinum neurotoxin serotype A.

Section: $\quad$ Drug Discovery and Translational Medicine 


\begin{abstract}
Small peptides patterned after the N-terminus of the synaptosomal protein of $25 \mathrm{kDa}$ (SNAP-25), a member of the protein complex implicated in $\mathrm{Ca}^{2+}$-dependent neuronal exocytosis, inhibit in vitro the release of neuromodulators involved in pain signaling, suggesting an in vivo analgesic activity. Here, we report that compound DD04107, a 6mer palmitoylated peptide that blocks the inflammatory recruitment of ion channels to the plasma membrane of nociceptors, and the release of calcitonin gen-related peptide (CGRP) from primary sensory neurons, displays potent and long-lasting in vivo antihyperalgesia and anti-allodynia in chronic models of inflammatory and neuropathic pain, such as the complete Freund's Adjuvant, osteosarcoma, chemotherapy and diabetic neuropathic models. Subcutaneous administration of the peptide produced a dose-dependent anti-hyperalgesic and anti-allodynic activity that lasted $\geq 24 \mathrm{~h}$. The compound showed a systemic distribution, characterized by a bicompartmental pharmacokinetic profile. Safety pharmacology studies indicated that the peptide is largely devoid of side effects, and substantiated that the in vivo activity is not due to locomotor impairment. Therefore, DD04107 is a potent and long-lasting antinociceptive compound that displays a safe pharmacological profile. These findings support the notion that neuronal exocytosis of receptors and neuronal algogens pivotally contribute to chronic inflammatory and neuropathic pain, and imply a central role of peptidergic nociceptor sensitization to the pathogenesis of pain.
\end{abstract}


JPET\#190678

\section{Introduction}

Nociceptor sensitization is one of the central events underlying pain pathogenesis (Gold and Gebhart, 2010). Tissue damage-mediated modulation of the threshold and magnitude of nociceptive responses to noxious stimuli is pivotal for the development of neural hyperexcitability (Gold and Gebhart, 2010). It is well documented that pro-inflammatory mediators are major players in nociceptor potentiation by acting on neuronal receptors which, in turn, activate signaling pathways that affect the metabolic and functional state of peripheral sensory neurons (Hucho and Levine, 2007), leading to altered patterns of neuronal activity. This shift is caused by changes in the activity of ion channels that may arise from variations in channel gating, channel distribution and/or channel density (Premkumar et al. 2004; Von Buren et al. 2005; Zhang et al. 2005; Camprubi-Robles et al. 2009). In addition, sensitized nociceptors, especially the peptidergic subpopulation, display an efferent function characterized by the release of the pro-inflammatory peptides substance P (SP) and calcitonin gene-related peptide (CGRP) that further enhance pain signals (Kilo et al., 1997; Meng et al. 2009). These neuropeptides also contribute to chronic pain conditions that apparently do not display an inflammatory process (Sprenger and Goadsby, 2009).

Neuronal release of pro-inflammatory peptides is carried out through a $\mathrm{Ca}^{2+}-$ dependent exocytotic mechanism that is sensitive to the proteolytic action of botulinum neurotoxins, as well as to small molecules that target the soluble $\mathrm{N}$-ethylmaleimide sensitive attachment protein receptor (SNARE) complex (Meng et al. 2007; CamprubiRobles et al. 2009). Noteworthy, a similar exocytotic mechanism is involved in the inflammatory recruitment of TRPV1 to the nociceptor surface (Van Buren et al. 2005; Zhang et al. 2005; Camprubi-Robles et al. 2009). The unequivocal contribution of regulated neuronal exocytosis to nociceptor excitability and, therefore, to pain pathogenesis is further supported by the anti-nociceptive and analgesic activity reported for botulinum neurotoxin A (BoNT A) (Argof 2010; Querama et al. 2010; Torgovnick et al. 2010; Yoon et al. 2010). However, the therapeutic use of this potent neurotoxin is often limited to local, well-controlled applications due to its high toxicity and potential locomotor side effects (FDA alerts, www.fda.org). Therefore, there is a need to develop small molecules that down regulate the excessive $\mathrm{Ca}^{2+}$-dependent exocytosis occurring in chronic pain states, and display lower side effects. 
We have previously demonstrated that small peptides patterned after the $\mathrm{N}$ terminus of the synaptosomal protein of $25 \mathrm{kDa}$ (SNAP-25), a SNARE complex protein, are inhibitors of neuronal exocytosis by interfering with the formation of the vesicular fusion protein complex between synaptobrevin, syntaxin and SNAP-25 (Blanes-Mira et al. 2004). The palmitoylated-derivative DD04107 blocked the inflammatory sensitization of TRPV1 by pro-inflammatory agents in intact primary sensory neurons in culture by preventing the recruitment of a vesicular population of channels to the nociceptor surface (Camprubi-Robles et al. 2009). Accordingly, these results suggest that compound DD04107 may display anti-nociceptive function. In this study, we have addressed this issue and tested the in vivo anti-inflammatory and antinociceptive activity of DD04107 in models of chronic inflammatory and neuropathic pain. We found that a single dose of DD04107 given subcutaneously or intramuscularly significantly and long-lasting reduced the thermal and mechanical hyperalgesia, as well as the mechanical allodynia in these pain models. Pharmacokinetic analysis reveals a systemic distribution and safety pharmacology parameters did not reveal any significant side effect. Thus, compound DD04107 represents a novel class of a lead that may be therapeutically relevant for the treatment of chronic pain. Our findings also substantiate a pivotal role of neuronal exocytosis in pain pathogenesis. 
JPET\#190678

\section{Methods}

Drugs. DD04107 (palmitoyl-EEMQRR-NH2, DiverDrugs, Gavà, Spain), vincristine sulfate (Calbiochem), paclitaxel (Bisse Medical), morphine hydrochloride (Salars) and naltrexone hydrochloride (Sigma) were dissolved in saline and weighed as salt. Streptozotocine (Sigma) was dissolved in sodium citrate at pH 4.5. DD04107, naltrexone, morphine and their vehicle were administered subcutaneously (s.c.) at a volume of $5 \mathrm{ml} / \mathrm{kg}$. Vincristine, streptozotocine (STZ) and their vehicle were administered intraperitoneally (i.p.) at volume of $2 \mathrm{ml} / \mathrm{kg}$.

Use of animals. All experiments were approved by the Institutional Animal and Ethical Committee of the corresponding institutions where experiments were conducted or in compliance with the Italian regulatory system (D.L. vo 116 of 27/1/92, Art. 6), and were in accordance with the guidelines of the Economic European Community (86/609/EEC), the National Institute of Health, and the Committee for Research and Ethical Issues of the International Association for the Study of Pain. All parts of the study concerning animal care were performed under the control of veterinarians.

Housing of animals. Male Sprague-Dawley and Wistar rats (Harlan) were housed three a cage. Male CD1 mice, from Charles River Italy and C3H/He mice from CRI-FFA Spain, were housed four a cage. Animals, allowed to familiarize for at least 7 days before the start of experiments, were maintained under 12-hour circadian cycle of artificial light (7:00 a.m. $-7: 00$ p.m.), $22 \pm 2{ }^{\circ} \mathrm{C}, 55 \pm 10 \%$ relative humidity, 15-20 filtered air exchanges/hour. Rats and mice had free access to food and tap water. At the beginning of experiments the body weight was about 150-350 $\mathrm{g}$ for rats and 20-40 $\mathrm{g}$ for mice.

Carrageenan inflammatory model. Wistar rats $(\approx 150 \mathrm{~g})$ were used for the study. Carrageenan $(0.1 \mathrm{ml}$ of a $2 \%$ solution in physiological saline) was injected into the plantar surface of the right hind paw of the rats. Compounds were administered intramuscularly (i.m.) in the ipsilateral paw 30 min before carrageenan at the indicated doses. The volume of the paw was measured at the indicated times with a plethysmometer, and the anti-hyperalgesic activity was determined after $5 \mathrm{~h}$ with a Randall-Selitto analgesimeter (Ugo Basile, Varese, Italy). 
CFA inflammatory model. Wistar rats $(\approx 200 \mathrm{~g})$ were used for the study. CFA emulsion $(1: 1$ oil/saline, $0.5 \mathrm{mg} / \mathrm{ml})$ was injected into the plantar surface $(50 \mu \mathrm{L})$ (GarciaMartinez et al. 2006). DD04107 was administered at $1 \mathrm{mg} / \mathrm{kg}$ i.m. in the ipsilateral leg $24 \mathrm{~h}$ after CFA injection. Thermal hyperalgesia was monitored $24 \mathrm{~h}$ after CFA injection and up to $6 \mathrm{~h}$ after administering the peptide with an Ugo Basile Dynamic Plantar Aesthesiometer as reported (Garcia-Martinez et al. 2006). Briefly, rats were habituated to an apparatus consisting of individual Perspex boxes on an elevated glass table. A mobile radiant heat source was located under the table and focused on the hind paw. Paw withdrawal latencies were defined as the time taken by the rat to remove its hind paw from the heat source. A cutoff point of 25 seconds was set to prevent tissue damage. The mechanical allodynia was followed up to 5 days after DD04107 administration using the Von Frey fibers with the "up and down" method (GarciaMartinez et al. 2006). Rats were placed on a raised wire mesh grid $(6 \times 6 \mathrm{~mm} 2$ apertures) under plastic chambers. To quantify the mechanical sensitivity of the paw, hairs with different forces (in grams) were applied 10 times to the hind paw in ascending order of force. The frequency of withdrawal responses was monitored and represented as the response percentage. The hair was applied for 1 to 2 seconds, with an interstimulus interval of 5 to 10 seconds.

Vincristine neuropathy model. Sprague-Dawley rats $(\approx 300 \mathrm{~g})$ were used in this study. Vincristine administration produces a long-lasting neuropathic state that mimics vincristine-induced pain in human patients (Aley et al. 1996). Intraperitoneal injections of vehicle or $0.15 \mathrm{mg} / \mathrm{kg}$ vincristine sulfate were administered to rats three times a week for two weeks. After the baseline nociceptive threshold measurement, DD04107 was administered s.c. and rats underwent the Randall-Selitto test, at different times. The experimental groups were made up by 9 rats each: DD04107 at $0,0.1$ and $0.5 \mathrm{mg} / \mathrm{kg}$ was administered to vincristine-treated rats. The nociceptive threshold, expressed in grams, was measured by applying increasing pressure to the hind paws, using a Randall-Selitto analgesimeter. The parameter used to quantify the nociceptive threshold was defined as the pressure (in grams) at which the rat withdrew its paw. The value reported is the mean between the grams at which the rat withdrew the left and the right paw. 
Taxol neuropathy model. Sprague-Dawley rats $(\approx 250 \mathrm{~g})$ were used in this study. Taxol administration induces a long-lasting neuropathic state that mimics taxane-induced pain in human patients (Polomano et al. 2001). Paclitaxel was given to rats by intraperitoneal injections $(2 \mathrm{mg} / \mathrm{kg}$ dose, with a volume of $1 \mathrm{ml} / \mathrm{kg}$ ) on days $1,3,5$ and 7 for a total cumulative dose of $8 \mathrm{mg} / \mathrm{kg}$. Neuropathy developed over time and mechanical allodynia was monitored on day 27 after the first administration of the taxane. DD04107 was administered at $0.5 \mathrm{mg} / \mathrm{kg}$ s.c., and the mechanical allodynia was followed every 3 days (up to 12 days) with the "up and down" method using a 10g Von Frey filament (GarciaMartinez et al. 2006). The frequency of withdrawal responses was monitored and represented as the response percentage. The hair was applied for 1 to 2 seconds, with an interstimulus interval of 5 to 10 seconds. The maximum anti-allodynic effect that exerted by $100 \mathrm{mg} / \mathrm{kg}$ of gabapentin (i.p.) and the minimum the mechanical allodynia displayed by animals at day 27 after administration of paclitaxel and before instillation of the peptide.

Streptozotocin (STZ)-induced diabetes model. CD1 mice (30-40 g) were used in this study. Vehicle or $200 \mathrm{mg} / \mathrm{kg}$ STZ were administered to 16 and 47 overnight fasted mice, respectively. Blood glucose levels were measured 14 days after STZ injection by measuring the glucose concentration in a blood sample obtained by tail prick. Mice with glucose levels above $250 \mathrm{mg} / \mathrm{dL}$ were considered diabetic. Blood glucose levels were measured using a Glucometer Elite (Bayer) device. Vehicle was administered to two groups: vehicle- and STZ-treated mice. DD04107 at doses of 0.5 and $5 \mathrm{mg} / \mathrm{kg}$ was administered s.c. only to STZ-treated mice. Mechanical allodynia was determined at different times. The range of withdrawal response in diabetic mice was 1.1-2.1g, compared to the control mice range $4.1-5 \mathrm{~g}$. The incidence of allodynia in diabetic CD1 mice was $100 \%$.

Osteosarcoma model. C3H/He mice (20-25 g) were used in this study. NCTC 2472 osteosarcoma cells were cultured in NCTC 135 medium containing 10\% horse serum and passaged weekly according to ATCC guidelines. Cells were detached by scraping and centrifuged at $400 \mathrm{X}$ g. The obtained pellet was suspended in phosphate-buffered saline (PBS pH 7.2) and then used for intratibial injections (Menendez et al. 2003).

For cell inoculation to mice, anesthesia was induced by spontaneous inhalation of $3 \%$ isoflurane in an induction chamber and maintained by administering $1.5 \%$ 
isoflurane in oxygen through a breathing mask. A minimal skin incision was made in the right leg exposing the tibial plateau and a 22 gauge needle coupled to a Hamilton syringe with $10^{5}$ NCTC 2472 cells suspended in $5 \mu \mathrm{L}$ of PBS $1 \mathrm{X} \mathrm{pH} 7.2$ was used to inject the cells into the medullar cavity. Finally, acrylic glue was applied on the incised area of the tibial plateau and the surgical procedure was completed by stitching the knee skin. Control groups were injected $5 \mu \mathrm{L}$ of PBS containing $10^{5}$ NCTC 2472 osteosarcoma cells killed by quickly freezing and thawing three times without cryoprotection.

Mice were used at the particular times at which the measured nociceptive symptoms were detected. Thus, thermal hyperalgesia was studied 4 weeks after the inoculation of NCTC 2472 osteosarcoma cells whereas mechanical allodynia was assessed at week 2 (Curto-Reyes et al. 2010).

DD04107 was dissolved in saline $(2 \mathrm{mg} / \mathrm{ml})$ and administered s.c. in a volume of $10 \mathrm{ml} / \mathrm{kg} 4$ weeks after the inoculation of NCTC 2472 osteosarcoma cells for the thermal hyperalgesia studies, and 2 weeks after the inoculation of NCTC 2472 osteosarcoma cells for the mechanical allodynia studies.

The thermal hyperalgesia was monitored using the Unilateral Hot Plate (UHP) test, mice were gently restrained and the plantar side of the tested paw was placed on a hot plate surface as previously described (Menendez et al. 2002). The latency of paw withdrawal from the heated surface was manually recorded with a chronometer. The mean of two measurements of the withdrawal latencies of each hind paw separately and alternately performed at 2-min intervals was calculated. A cut-off time of 30 seconds was established as a means to prevent tissue damage. In order to obtain basal withdrawal latencies of about $14 \mathrm{~s}$, plate temperature was adjusted at $51.7 \pm 0.2^{\circ} \mathrm{C}$.

Mechanical allodynia in mice was assessed by applying von Frey filaments to the plantar side of the paws as previously reported (Curto-Reyes et al. 2010). Mice were placed on a wire mesh platform, covered with transparent plastic containers. A 25 minute period was allowed for habituation. The von Frey filaments $2.44(0.04 \mathrm{~g}), 2.83$ $(0.07 \mathrm{~g}), 3.22(0.16 \mathrm{~g}), 3.61(0.4 \mathrm{~g}), 4.08(1.4 \mathrm{~g})$ and $4.56(4 \mathrm{~g})$ were used and, starting with the 3.61 filament, six measurements were taken in each animal randomly starting in the left or right paw. Based on the previously described manual 'up and down' method (Curto-Reyes et al. 2010), the observation of a positive response (lifting, shaking or licking of the paw) after a 3 second-long application of a filament was 
followed by the application of the next thinner filament or the next thicker one if the response was negative.

Effect of morphine and DD04107 on the mechanical nociceptive threshold in rats. DD04107 was administered s.c. to Sprague-Dawley rats $(\approx 300 \mathrm{~g})$ at 0.5 and $5 \mathrm{mg} / \mathrm{kg}$. Morphine was administered s.c. at $3 \mathrm{mg} / \mathrm{kg}$ as reference drug. Naltrexone was used as opioid antagonist (Julius, 1979), and administered s.c. at $0.1 \mathrm{mg} / \mathrm{kg} 30 \mathrm{~min}$ before DD04107 or morphine administration. The nociceptive threshold, expressed in grams, was measured by applying increasing pressure to the left and right hind paws, using a Randall-Selitto analgesimeter.

Pharmacokinetics studies. Male Wistar $(\approx 300 \mathrm{~g})$ were used for pharmacokinetic studies. Twenty-four hours before drug administration, the rats were subjected to jugular vein cannulation with a $12-\mathrm{cm}$ long fragment of medical grade silicone tubing (Degania Silicone Europe GmbH, Regensburg, Germany; inner diameter: $0.5 \mathrm{~mm}$; outer diameter: $0.94 \mathrm{~mm}$ ). Anesthesia was induced before surgery by isoflurane inhalation. Under anesthesia, $3.4 \mathrm{~cm}$ of the cannula was introduced into the jugular vein toward the heart and the free end was subcutaneously conducted to the dorsal base of the neck, where it emerged; the exteriorized end was closed with a polyethylene plug. The cannula was permanently filled with heparinized $(20 \mathrm{IU} / \mathrm{ml})$ saline solution. After surgery and until drug administration, animals were kept on nonfasting conditions overnight with water freely available. In order to facilitate blood sampling of conscious rats, a 15-cm long silicon tube (bridge-tubing) was connected to the free end of the cannula.

A total of 14 animals and 99 plasma samples were employed in the study. Extemporaneous solutions were prepared by dissolving the corresponding amount of compound in saline solution. Two main groups of rats were randomly assigned to intravenous (i.v., $5 \mathrm{mg} / \mathrm{kg}$ ) and subcutaneous (s.c., $10 \mathrm{mg} / \mathrm{kg}$ ) administration. A second random assignation took place, $\mathrm{A}$ (administration and sampling period of time from 0 to $12 \mathrm{~h}$ ) or B (administration and sampling period of time from 12 to $288 \mathrm{~h}$ ).

Blood samples $(0.4 \mathrm{ml})$ were drawn from the jugular vein cannula with heparinised syringes at $0,0.25,0.5,1,1.5,2,4,8,12,18,24,48,72,96,120,192,240$ and $288 \mathrm{~h}$ after the DD04107 administration. After each sample was drawn, the blood volume was replaced with the same volume of a saline solution. The number of samples 
processed within a $24 \mathrm{~h}$ period to obtain the curve of the plasma level of DD04107 was never higher than 11. After collection, each blood sample was centrifuged at $3500 \mathrm{rpm}$ for $10 \mathrm{~min}$ and the plasma was transferred to an unused polypropylene tube and stored at $-20{ }^{\circ} \mathrm{C}$ until it was assayed for DD04107 content.

Analysis of data was performed by noncompartmental analysis with the WinNonLin V.2.1 program. The area under the plasma concentration-time curve from immediately pre-dose (time zero) to the last quantifiable concentration $\left(\mathrm{AUC}_{0-\mathrm{t}}\right)$, the peak concentration of DD04107 $\left(\mathrm{C}_{\max }\right)$, and the apparent terminal elimination phase rate constant $\left(\lambda_{z}\right)$ was obtained for each animal. The $\lambda_{z}$ was derived from the log-linear disposition phase of the concentration-time curve by least-squares regression analysis with visual inspection of the data to determine the appropriate number of data points for the calculation of $\lambda_{z}$. At least three points in the terminal elimination phase were required for calculation of $\lambda_{\mathrm{z}}$. The $\mathrm{AUC}_{0-\mathrm{t}}$ was calculated by using the log-linear trapezoidal rule.

CGRP release from primary sensory neurons in culture. Neurons from neonatal wistar rat dorsal root ganglion were obtained (Camprubi-Robles et al. 2009), and seeded at a density of 15,000 per well in a 96-well plate incubated at $37^{\circ} \mathrm{C}$ in humidified atmosphere with $5 \% \mathrm{CO}_{2}$. Experiments were carried out in Kreb's-HEPES buffer (in mM: $110 \mathrm{NaCl}, 4.5 \mathrm{KCl}, 2 \mathrm{CaCl}_{2}, 1.2 \mathrm{MgSO}_{4}, 1.2 \mathrm{KH}_{2} \mathrm{PO}_{4}, 25 \mathrm{NaHCO}_{3}, 11.7 \mathrm{D}-$ glucose, 5 HEPES pH 7.4). Previous to the quantification of CGRP release, cells were treated with the lipopeptides $(10 \mu \mathrm{M}$ for $1 \mathrm{~h})$ contained in the culture medium. After an extensive wash with Kreb's-HEPES buffer, cells were exposed to $1 \mu \mathrm{M}$ capsaicin in Kreb's-HEPES buffer at $37^{\circ} \mathrm{C}$ for $5 \mathrm{~min}$. Aliquots of $100 \mu \mathrm{l}$ per well were collected for each treatment at $4{ }^{\circ} \mathrm{C}$ and the CGRP content was determined immediately after the end of the experiment using the commercially available CGRP EIA kit (Spi-Bio Inc., France; Cayman, USA) according to the manufacturer's protocol. The CGRP in eluates was pre-incubated with the antibody-coated plate overnight at $4^{\circ} \mathrm{C}$ before being reacted with the tracer antibody (the AchE-conjugated antibody). One hundred microliter of standards and samples were added to individual wells in a 96-well microtiter plate and incubated at $4^{\circ} \mathrm{C}$ for overnight. Two hundred microliter of tracer antibody was then added and incubated overnight at $4^{\circ} \mathrm{C}$. Ellman's reagent was then added to the wells and incubated $30 \mathrm{~min}$ to $1 \mathrm{~h}$ at RT with shaking. A standard curve was generated for each assay and the concentration of CGRP in each sample was determined using the standard 
curve. The values were expressed as the mean of four determinations. Plates were read at $450 \mathrm{~nm}$ with a microplate spectrophotometer and results were analyzed using GraphPad Prism 4.0 programme. The CGRP detection level of the method is about 2 $\mathrm{pg} / \mathrm{ml}$ and all the measured CGRP values were at least twofold the detection limit.

Isolation of rat atria and aorta rings. Organ bath preparations were performed as described (Borges et al 1989). Briefly, animals were killed by decapitation. The heart was rapidly removed and the right atria placed in a $4 \mathrm{ml}$ organ bath cup. A basal tension of $1 \mathrm{~g}$ was applied and the contractions monitored using an isometric transducer. Temperature was set at $34^{\circ} \mathrm{C}$ and the Krebs-bicarbonate solution (in mM: $119 \mathrm{NaCl}, 4.7$ $\mathrm{KCl}, 1.2 \mathrm{MgSO}_{4}, 1.2 \mathrm{KH}_{2} \mathrm{PO}_{4}, 2.5 \mathrm{CaCl}_{2}, 25 \mathrm{NaHCO}_{3}$ and 11 Glucose) continuously bubbled with $95 \% \mathrm{O}_{2}, 5 \% \mathrm{CO}_{2}$ mixture to maintain the $\mathrm{pH}$ at 7.4. Thoracic aortas were excised and cleaned of surrounding fat and connective tissues. Slices of $\approx 2 \mathrm{~mm}$ were cut with care to avoid the endothelial damage and mounted in the organ bath as described above using Krebs-bicarbonate solution and applying a basal tension of $1 \mathrm{~g}$ (Borges et al 1989).

Locomotor activity. Wistar rats were placed in the Rotarod (a cylinder that can rotate at constant or accelerating speeds) and the speed increased from 4 to $40 \mathrm{rpm}$ over a period of $300 \mathrm{~s}$. The time, in seconds, at which each animal fell off the rungs was recorded with a maximum cut-off of $600 \mathrm{~s} 1$ day and 8 days after the administration of the different treatments (Boix et al. 2010).

The ability of rats to pass through a narrow beam to reach a dark box was evaluated. To force rats to pass through the beam, a white light illuminated the beginning of the beam. The wooden square beam $(2 \times 100 \mathrm{~cm})$ was elevated to a height of $1 \mathrm{~m}$ above the floor. The time to cross the beam and the number of forelimb and hindlimb foot faults were recorded 1 day and 8 days after the administration of the different treatments. A fault was defined as any foot slip off the top surface of the beam or any limb use on the side of the beam. Four trials were performed before recording the results to habituate the rats to the beam and to let them to know the existence of the dark box at the end of the beam. The interval between trials was 5 minutes.

For the open field measurements, the animals were placed in an open-field activity chamber $(43 \times 43 \times 30.5 \mathrm{~cm})$ and allowed to explore for 60 minutes. Activity was 
detected by arrays of infrared motion detectors, with two arrays $1 \mathrm{~cm}$ above the floor of the chamber and another array $6 \mathrm{~cm}$ above the floor. Motor activity was recorded during 1 hour on 1 day and 8 days after the administration of the different treatments. The apparatus recorded different parameters of motor activity; ambulatory, vertical and stereotypic activities, ambulatory episodes, average velocity of ambulatory activity and the total distance travelled. One ambulatory count was recorded when the rats interrupted 3 consecutive infrared beams. One vertical count was recorded when the rats activated the above detectors (Ahabrach et al. 2010). For all these locomotor tests, compound DD04107 was administered s.c. at $10 \mathrm{mg} / \mathrm{kg}$.

Learning and memory. Wistar rats were used. The object recognition test was performed as described (Garcia-Ayllon et al. 2008). This test exploits the tendency of rats to preferentially explore novel elements of their environment. Thus, when a rat was presented with both a novel and a recently presented familiar object, it spent significantly longer time exploring the novel object. The familiar object was presented in a previous training session $4 \mathrm{~h}$ before the test. The percentage of time exploring the non-familiar object in the training session over total exploration time (exploration time of the familiar plus the non-familiar objects) is represented. This test was performed 2 , 3 or 4 days after the administration of the test item.

The spatial learning and spatial memory tests were carried out using a circular pool (160 cm diameter, $40 \mathrm{~cm}$ height) arbitrarily divided into four quadrants. Water opacity was obtained adding powdered milk. A transparent Plexiglas platform, $10 \mathrm{~cm}$ in diameter, was immersed $2 \mathrm{~cm}$ under the water surface at the centre of one quadrant during training sessions. The learning test was carried out as follows; the first day was the day of administration of the different treatments. 24 hours later rats were put in the water three times for $20 \mathrm{~s}$ only to adapt to water (pretraining day). Then the rats were trained to learn the fixed location of the invisible platform during 4 consecutive days ( 2 , 3, 4 and 5 days after administration of the treatments). Each training trial involved placing the rat into the pool facing the wall at one of the three quadrants lacking the platform. A different starting point was randomly used on each trial. Training consisted of six swims per day, with an intertrial interval of $10 \mathrm{~min}$. Each animal was allowed a maximum of $120 \mathrm{~s}$ to find the platform and was left for $20 \mathrm{~s}$ on the platform. The purpose of this is to measure the time rats take to learn where the invisible platform is 
placed and how long it takes for them to find it. The time needed to find the hidden platform was recorded manually and used as a measure of the learning of the task. If a rat failed to locate the platform within $120 \mathrm{~s}$ it was then manually guided to the platform by the researcher. Twenty hours after the last training trial (the $6^{\text {th }}$ day after administration of the treatments), the platform was removed from the pool and rats were allowed to swim for 90 seconds in the pool. The time spent by rats swimming in the quadrant where the platform was located during the training period was recorded. For these learning and memory tests, compound DD04107 was administered s.c. at 10 $\mathrm{mg} / \mathrm{kg}$.

Receptor binding. Receptor competitive binding assays and hERG channel activity were carried out by CEREP. For binding assays a panel of 55 neuronal receptors. Compound DD04107 was tested at $10 \mu \mathrm{M}$. For hERG channel activity recordings, compound DD04107 was tested at 0.5 and $5 \mu \mathrm{M}$.

Data evaluation. All behavioral experiments were carried out blindly with randomization of the animals. Data expressed as mean \pm sem. Dose-response and timecourse were analyzed using two-way repeated measures ANOVA, followed by Post hoc test unless otherwise indicated. Data were also calculated as area under curve (AUC), and one-way ANOVA followed by the Dunnett post hoc test was used as statistical analysis. Statistical significance was set at $\mathrm{p}<0.05$. The Graphpad Prism 5.0 software package was used for statistical analysis. 


\section{Results}

DD04107 attenuated the inflammation and mechanical hyperalgesia induced by carrageenan. Because compound DD04107 is an inhibitor of neuronal exocytosis that blocks the inflammatory recruitment of TRPV1 channels (Camprubi-Robles et al., 2009), we first determined the in vivo anti-inflammatory and anti-hyperalgesic activity in the carrageenan inflammatory model. For inflammatory pain models we used Wistar rats since Sprague-Dawley rats show lower inflammatory responses probably due to lower TNF- $\alpha$ expression and B-cell responses (Zhu et al. 1998). Injection of carrageenan in the rat paw induces an inflammatory process that resulted in a notable increase of the paw volume (Figs. 1A and 1B) along with mechanical hypersensitivity (Fig. 1C). The non-steroidal anti-inflammatory agent diclofenac at $10 \mathrm{mg} / \mathrm{kg}$ significantly reduced the increment in paw volume. Notably, peptide DD04107 displayed identical anti-inflammatory activity as evidenced by the attenuating effect of $5 \mathrm{mg} / \mathrm{kg}$ (Figs. 1A and 1B). In addition, compound DD04107 completely reversed the mechanical hypersensitivity induced by carrageenan, without affecting the threshold of the contralateral paw (Fig. 1C). These results indicate an in vivo anti-inflammatory and anti-nociceptive activity of peptide DD04107.

\section{DD04107 mitigated the thermal hyperalgesia and mechanical allodynia provoked}

CFA. To further investigate the in vivo anti-nociceptive activity of DD04107, we used CFA-induced inflammation as a model of chronic inflammatory pain (Garcia-Martinez et al. 2006). Intraplantar injection of CFA produces a peripheral inflammatory process that results in thermal hyperalgesia and mechanical allodynia, with an onset of $24 \mathrm{~h}$ after CFA inoculation and may last up to 25 days depending on the adjuvant dose (Garcia-Martinez et al. 2006). The underlying mechanism involves the release of proinflammatory peptides along with the potentiation of TRPV1 activity in nociceptors (Ji et al. 2002). As illustrated in Fig. 1D, intraplantar injection of CFA resulted in a pronounced thermal hyperalgesia in the ipsilateral paw as revealed by $\approx 50 \%$ the decrease latency to a heat source. Intramuscular administration of $5 \mathrm{mg} / \mathrm{kg}$ DD04107 in the ipsilateral leg resulted in a relatively slow $(\geq 4 \mathrm{~h})$, but virtually complete abrogation, of the thermal hypersensitivity. Furthermore, the CFA-induced mechanical allodynia was significantly attenuated by the peptide, as evidenced by the increase of the mechanical threshold 24 hours after CFA administration (Fig. 1E). Notably, the anti- 
allodynic activity of a single dose of DD04107 remained at least up to 5 days after its administration, as revealed by both the increase in the mechanical threshold (Figs. 1E) and the decrease of the animal response to stronger mechanical stimuli (Fig. 1F). When the non-palmitoylated peptide was used, we observed a 50\% lower attenuation of the heat hyperalgesia (latency of $11.2 \pm 0.5 \mathrm{~s}, \mathrm{n}=8$, vs. vehicle, $7.6 \pm 0.7 \mathrm{~s}, \mathrm{n}=8$ ) than that DD04107 (15.1 $\pm 0.9 \mathrm{~s}, \mathrm{n}=8)$, but that appeared at shorter times (1h upon administration). This finding is consistent with the faster delivery and lower permeability of the nonpalmitoylated peptide, and further implies that the anti-nociceptive activity is due to the peptide and not to an alteration of the cellular membrane as a result of lipid-mediated peptide anchoring. Together, these results indicate that compound DD04107 displays anti-hyperalgesic and anti-allodynic activity against inflammatory pain, and that this activity appears to be long lasting.

\section{DD04107 reduced the thermal hyperalgesia and mechanical allodynia induced by}

an osteosarcoma. To expand the in vivo anti-nociceptive activity of DD04107, we next evaluated its effect in an osteosarcoma pain model. Intratibial injection of tumor cells in mice provokes a tumor that is accompanied by both thermal hyperalgesia and mechanical allodynia (Fig. 2). The underlying mechanism of bone cancer appears to involve an inflammatory process induced by tumor cells (Ghilardi et al. 2005). Compound DD04107, administered s.c., was able to significantly attenuate the thermal hyperalgesia in animals bearing the osteosarcoma in a dose-dependent manner (Figs. 2A and $2 \mathrm{~B}$ ). Note that, at a dose of $0.3 \mathrm{mg} / \mathrm{kg}$, the peptide completely reverted the thermal hypersensitivity (Fig. 2B), while at $0.1 \mathrm{mg} / \mathrm{kg}$ it displayed significant anti-nociception at 2-4 days after administration (Fig. 1A). A similar result was observed for the mechanical allodynia that was fully reversed by $1 \mathrm{mg} / \mathrm{kg}$ DD04107 (Figs. 2C and 2D). Akin to the CFA model, the analgesic activity displayed of a single peptide dose started 24 post-administration and lasted up to 7-8 days. These observations corroborate that DD04107 has potent and long-lasting in vivo anti-hyperalgesic and anti-allodynic activity against chronic inflammatory pain.

\section{DD04107 decreased the mechanical hyperalgesia induced by chemotherapeutic} agents. Drugs used to treat cancer, such as vincristine and paclitaxel produce a doselimiting peripheral neuropathy characterized by mechanical hypersensitivity (Siau et al. 2006; Swain and Arezzo, 2008). This neuropathy frequently causes the interruption of the chemotherapeutic treatment. Since compound DD04107 displays important in vivo 
anti-hyperalgesic activity, we questioned whether it was also active attenuating the mechanical hyperalgesia induced by chemotherapeutics. To address this issue, we used two models, vincristine- and paclitaxel-induced peripheral neuropathies, and tested the effect of compound DD04107 on the mechanical hypersensitivity. As depicted in Fig. $3 \mathrm{~A}$, the peptide attenuated the mechanical hyperalgesia in a dose-dependent manner in animals with a vincristine-induced neuropathy. Considerable attenuation of the mechanical hyperalgesia could be observed at a dose as low as $0.1 \mathrm{mg} / \mathrm{kg}$ (Figs. 3A and 3B). Notably, as for the CFA and osteosarcoma models, the activity of a single dose was long lasting, with significant anti-nociception up to 10 days after administration (Fig. 3A). A Similar anti-nociceptive activity was observed on the mechanical hypersensitivity developed by animals displaying paclitaxel-induced neuropathy (Figs. 3C and 3D). Taken together, these data suggest that compound DD04107 reduces the effects of the peripheral neuropathy induced by anti-cancer agents, and suggest a therapeutic use for this type of neuropathic pain.

DD04107 ameliorated the mechanical sensitivity of a diabetic neuropathy. We also investigated the effect of the peptide on the mechanical allodynia associated to a diabetes-induced neuropathy (Suri and Szallasi, 2008; Pabbidi et al. 2008). Administration of STZ into mice increases the plasma glucose levels above $250 \mathrm{mg} / \mathrm{dL}$ producing overtime a peripheral neuropathy exhibiting conspicuous mechanical hypersensitivity (Fig. 4A). Subcutaneous administration of DD04107 significantly reduced the mechanical allodynia in a dose-dependent manner (Fig. 4), with a maximum effect at $4 \mathrm{~h}$ after instillation of 0.5 and $5 \mathrm{mg} / \mathrm{kg}$ of compound. At variance with the other pain models, the activity of the peptide at the highest dose $(5 \mathrm{mg} / \mathrm{kg})$ lasted up to $24 \mathrm{~h}$ post-administration (Fig 4A). A residual analgesic activity could be seen with 5 $\mathrm{mg} / \mathrm{kg}$ after 5 days that did not reach significance, although the AUC at this dose exhibited a statistical difference (Fig. 4B). A similar result was obtained with when STZ-induced diabetic Sprague-Dawley rats were used (data not shown). These findings show that compound DD04107 was also active reducing the mechanical hypersensitivity produced by a diabetic neuropathy.

DD04107 does not act on opioid receptors. Compound DD04107 was shown to block the inflammatory potentiation of TRPV1 in primary sensory neurons in culture (Camprubi-Robles et al. 2009). Because the peptide inhibits $\mathrm{Ca}^{2+}$-dependent neuronal exocytosis by interfering with the formation of the SNARE complex (Blanes-Mira et al. 
2004), it effectively inhibited capsaicin-induced CGRP release from primary cultures of nociceptors in a dose-dependent manner (Fig. 5A). To further substantiate this mechanism of action, we evaluated whether DD04107 interacted with a battery of neuronal receptors. The binding screen on a panel of 60 neuronal receptors was carried out at Cerep. This assay, based on a competitive receptor binding approach, revealed that the peptide interacted with the adenosine type 3 receptor (A3), CxCR2, noreprinephine and dopamine transporters, and the $\delta 2, \kappa$ and $\mu$ opioid receptors with an $\mathrm{IC}_{50}$ larger than $10 \mu \mathrm{M}$.

Since compound DD04107 appears to interact with opioid receptors, it may suggest a contribution of this signaling pathway for the compound in vivo activity. To evaluate this issue, we investigated the effect of naltrexone on the anti-nociceptive activity of $5 \mathrm{mg} / \mathrm{kg}$ of the peptide (Fig. 5B). At this dose, DD04107 produced an increase in the mechanical threshold during the first $24 \mathrm{~h}$. This effect was virtually identical to that displayed by $3 \mathrm{mg} / \mathrm{kg}$ of morphine. Pre-treatment of the animals with 1 $\mathrm{mg} / \mathrm{kg}$ naltrexone, a potent opioid receptor antagonist (Julius 1979), completely abolished the effect of morphine, but did not alter the mechanical anti-nociception provoked by the peptide. Taken together, these results suggest that compound DD04107 does not act through a central opioid signaling pathway, and suggest that a peripheral mechanism of action may underlie the in vivo activity.

DD04107 pharmacokinetics. To further understand the pharmacodynamic properties of the peptide, we next investigated its pharmacokinetics after intravenous and subcutaneous administration. As seen in Fig. 6A, intravenous injection of DD04107 resulted in rapid decay of the plasma concentration that was detectable up to $40 \mathrm{~h}$. The data were well fitted to a two-compartment model, with fast initial $\alpha$ decay, followed by a slower $\beta$ phase. The pharmacokinetic parameters are reported in Table I. Subcutaneous administration of the compound also displayed a bicompartmental profile (Fig. 6B, Table I). For this instillation route, the maximum concentration for a $10 \mathrm{mg} / \mathrm{kg}$ dose was $16 \mu \mathrm{M}$, and $t_{\max }$ of $10.5 \mathrm{~h}$ after administration (Table I). Inspection of the curve shows that the compound was detectable in plasma samples up to $200 \mathrm{~h}$ after administration, consistent with a long lasting presence in the plasma in accordance with the relatively modest rate of clearance (Table I). In addition, a second plasma peak appears at $120 \mathrm{~h}$ post-administration, presumably due to a release of the peptide from 
subcutaneous fat store. Together, these observations suggest that compound DD04107 administered s.c. has a significant and prolonged systemic exposure.

DD04107 safety pharmacology profile. We next evaluated the safety pharmacology profile of the compound. First, an Irwin test to evaluate any behavioral effect of the peptide was performed. This test was performed at 3 doses of compound DD04107, from 0.5 to $50 \mathrm{mg} / \mathrm{kg}$, and at 30 and $240 \mathrm{~min}$ post-administration. None of these doses produced any significant alteration on the parameters evaluated (Table II). A particular attention was paid to body temperature and thermal nociception. As displayed in Figs. 7A and B, neither of these parameters was affected by DD04107 up to $50 \mathrm{mg} / \mathrm{kg}$.

To assess the cardiovascular safety of the peptide, the effect of therapeutic concentrations on the hERG tail currents was evaluated. DD04107 did not affect these currents at therapeutic concentrations (0.5 and $5 \mu \mathrm{M})$ (Fig. 8A). Similarly, we investigated the atrial contractility in control conditions and the presence of $300 \mathrm{nM}$ adrenaline. Figure 8B shows that compound DD04107 did not affect the beats per minute at concentrations as high as $30 \mu \mathrm{M}$ (Fig. 8B).

To conclude this evaluation, we also investigated if the compound affected the locomotor coordination of the animals, as well as if it altered their learning and memory abilities. Table III summarizes all the parameters monitored and indicates that none of them was changed by the subcutaneous administration of $10 \mathrm{mg} / \mathrm{kg}$ of DD04107. A similar result was obtained from the learning and memory tests, namely the object recognition, spatial learning and spatial memory (Table IV). Collectively, all these observations indicate that compound DD04107 is an analgesic molecule with an acceptable safety pharmacology profile. 


\section{Discussion}

A pivotal aim in the pharmacological management of pain pathogenesis is to control the molecular events that cause and are associated with nociceptor sensitization (Gold and Gebhart, 2010). Sensitized nociceptive neurons are characterized by a remarkable high excitability due to both a decrease in their activation threshold and an increase in their firing frequency Gold and Gebhart, 2010). These changes are produced by alterations in the distribution, density and gating of ion channels responsible for action potential generation and propagation. Cumulative evidence indicates that $\mathrm{Ca}^{2+}$ regulated exocytosis of ionotropic receptors to the neuronal surface is a central mechanism contributing to neuronal excitability. In primary sensory neurons, inflammatory sensitization involves the exocytotic recruitment of ion channels to the plasma membrane, which augments channel density and enhances the neuronal response pattern (Zhang et al. 2005; Van Buren et al. 2005; Camprubi-Robles et al. 2009. In addition, sensitized peptidergic nociceptors exocytotically release pro-inflammatory peptides, which in turn, stimulate the secretion of pro-inflammatory mediators from immune cells that further potentiate nociceptor excitability (Kilo et al. 1997). Collectively, these observations signal to regulate neuronal exocytosis as a valuable therapeutic target to attenuate nociceptor sensitization. In support of this notion, botulinum neurotoxins have been shown to exhibit analgesic activity (Argoff, 2010; Qerama et al. 2010; Yoon et al. 2010).

The most salient contribution of our study is that a small peptide patterned after the N-end of SNAP-25, a SNARE complex protein involved in vesicular fusion, displays important in vivo anti-nociceptive activity in animal models of inflammatory and neuropathic pain. This peptide was shown to interfere with the formation of the SNARE complex, thus inhibiting $\mathrm{Ca}^{2+}$-mediated neuronal vesicle fusion (Blanes-Mira et al. 2004). To study its cellular activity in intact neurons, the peptide was palmitoylated to favor its tethering to the plasma membrane (Camprubi-Robles et al. 2009). The palmitoylated peptide notably inhibited the inflammatory potentiation of TRPV1 channels in cultured nociceptors by blocking the exocytotic recruitment of channels to the neuronal surface (Camprubi-Robles et al. 2009). Here, we found that a single dose $(0.1-5 \mathrm{mg} / \mathrm{kg})$ of the palmitoylated peptide significantly decreased the thermal hyperalgesia and mechanical allodynia in animals that were locally inflamed with CFA or that developed a tibial osteosarcoma. Noteworthy, the anti-hyperalgesic and anti- 
allodynic effects of the peptide were seen at doses as low as $0.1 \mathrm{mg} / \mathrm{kg}$, was dosedependent and long lasting (a single dose exhibited analgesic activity for up to 7 days). Likewise, substantial mechanical anti-hyperalgesia was observed when the compound was tested in models of neuropathic pain such as those produced by chemotherapeutic agents and diabetes. Both vincristine and paclitaxel-induced mechanical hyperalgesia were significantly reduced by a single subcutaneous dose of the compound for up to 12 days. The in vivo activity of DD04107 was also observed in the model of diabetic neuropathy, although it displayed a shorter duration ( $<5$ days at $5 \mathrm{mg} / \mathrm{kg}$ ) as compared with the other chronic pain models. The shorter duration of the analgesic activity of the peptide in this neuropathic model is not clear, although it could be influenced by the mice strain used. It should be mentioned that different strains rats and mice were used in this study to discard a strain-related activity of the compound. Taken together, these findings indicate that compound DD04107 is a potent anti-nociceptive molecule suitable for the treatment of chronic inflammatory and neuropathic pain.

A concern with compounds that block neuronal exocytosis is the potential deficits on the locomotor activity and coordination due to relaxation of muscles (FavreGuilmard et al. 2009). In addition, motor impairment could be the major mechanism underlying anti-nociception, instead of a nociceptive reflex. However, we found that the subcutaneous administration of the peptide did not affect motor performance at the doses tested. Overall, compound DD04107 displayed a favorable therapeutic index, since we could not detect any behavioral alteration at doses 100-fold larger than the therapeutic dose, nor significant potential cardiac effects or central alterations. Furthermore, the body temperature and the heat nociception were not altered, consistent with the notion that DD04107 does not affect TRPV1 channel activity, although it efficiently blocks the inflammatory recruitment of TRPV1 and other thermoTRPs and ions channels to the neuronal surface (Camprubi-Robles et al. 2009). Accordingly, compound DD04107 appears to be a safe and potent compound that attenuates hyperalgesia and allodynia by blocking a nociceptive reflex.

A remarkable and unexpected property of compound DD04107 is its long lasting in vivo activity. This prolonged duration may be due to a favorable pharmacokinetic profile of the compound or to its stabilization in the cell membrane or a contribution of both. We could detect the palmitoylated peptide in plasma samples up to $200 \mathrm{~h}$ after subcutaneous administration, suggesting that the compound is probably stored in a fat 
reservoir from where it could be slowly released. However, it should be mentioned that the plasma concentration at these long post-administration times appears significantly below the in vitro therapeutic concentration. Thus, although the pharmacokinetic profile is consistent with a long lasting pharmacodynamic effect, we cannot rule out that stabilization of the peptide in the plasma membrane of sensory neurons also contributes to the long duration of its in vivo activity. This tenet is backed up by the reported stabilizing effect that palmitoylation endows to peptides (Covic et al. 2002; Huster et al. 2003). Ongoing experiments in our laboratory are addressing this exciting hypothesis.

Our findings in the four pain models used, along with the results reported for the anti-nociceptive activity of botulinum neurotoxins(Argoff, 2010; Qerama et al. 2010; Yoon et al. 2010; Carmichael et al 2010; Favre-Guilmard et al. 2009; Mika et al. 2011; Torgovnick et al. 2010; Yuan eta al. 2009), support the tenet that neuronal exocytosis of receptors and channels and/or pro-inflammatory neuronal peptides plays a pivotal role in the development and maintenance of chronic inflammatory and neuropathic pain, and implies a central contribution of peptidergic nociceptor sensitization in the pathogenesis of pain. However, we could not discard an effect of these compounds on nonpeptidergic nociceptors, where they can also down regulate the function of their peripheral terminals. For instance, it is known that botulinum neurotoxins may produce axonal retraction, which may promote a peripheral denervation that may contribute to its analgesic activity. Compound DD04107 may have a similar influence on nonpeptidergic nociceptors, although we have seen in vitro an effect on neuronal morphology similar to a denervation only at high peptide concentrations (100 $\mu \mathrm{M}$, data not shown). Alternatively, the possibility that DD04107-evoked anti-nociception might be due to a central effect on the opioid signaling system was discarded because DD04107 mechanical anti-nociception was insensitive to naltrexone, a potent antagonist of opioid receptors. This result suggests a peripheral action of the peptide, although a central effect, for instance, at the spinal cord, cannot be ruled out. Nonetheless, additional cellular and molecular data are needed to further unveil the underlying mechanism of the potent anti-nociceptive activity exerted by inhibitors of neuronal exocytosis.

In conclusion, we have shown that a small peptide that blocks neuronal exocytosis with moderate efficacy potently attenuates the hyperalgesia and allodynia phenomena associated to chronic pain. At variance with botulinum neurotoxins that 
have to be administered locally to avoid side effects, compound DD04107 exhibits a good and prolonged systemic action, devoid of major side effects. This property, along with its wide therapeutic applications and pharmacological profile, implies that compound DD04107 is an excellent lead for further analgesic drug development for the treatment of chronic inflammatory and neuropathic pain.

Acknowledgements. We thank to Reme Torres for her contribution to the studies on the CFA model.

\section{Authorship Contributions.}

Participated in research design: Ponsati, Carreño, Baamonde, Borsini, De la Peña, Felipo, Planells-Cases, Ferrer-Montiel.

Conducted experiments: Curto-Reyes, Valenzuela, Duart, Beltran, Cauli, Fernandez, Caprioli, Di Serio, Veretchy, Barros.

Contributed new reagents or analytic tools: Van den Nest

Performed data analysis: Menendez, Borges, Baamonde, Felipo.

Wrote or contributed to the writing of the manuscript: Ponsati, Carreño, Ferrer-Montiel. 
JPET\#190678

\section{References}

Ahabrach H, Piedrafita B, Ayad A, El MN, Errami M, Felipo V, Llansola M (2010). Chronic hyperammonemia alters the circadian rhythms of corticosteroid hormone levels and of motor activity in rats. $J$ Neurosci Res 88:1605-1614.

Aley KO, Reichling DB, Levine JD (1996). Vincristine hyperalgesia in the rat: a model of painful vincristine neuropathy in humans. Neuroscience 73:259-265.

Argoff C (2010). The emerging use of botulinum toxins for the treatment of neuropathic pain. Pain Med 11:1750-1752.

Blanes-Mira C, Merino JM, Valera E, Fernandez-Ballester G, Gutierrez LM, Viniegra S, Perez-Paya E, Ferrer-Montiel A. (2004) Small peptides patterned after the Nterminus domain of SNAP25 inhibit SNARE complex assembly and regulated exocytosis. J Neurochem 88:124-135.

Boix J, Cauli O, Felipo V (2010). Developmental exposure to polychlorinated biphenyls 52, 138 or 180 affects differentially learning or motor coordination in adult rats. Mechanisms involved. Neuroscience 167:994-1003.

Borges R, von GH, Knight DE (1989). Tissue selectivity of endothelin. Eur J Pharmacol 165:223-230.

Camprubi-Robles M, Planells-Cases R, Ferrer-Montiel A (2009). Differential contribution of SNARE-dependent exocytosis to inflammatory potentiation of TRPV1 in nociceptors. FASEB J 23:3722-3733.

Carmichael NM, Dostrovsky JO, Charlton MP (2010). Peptide-mediated transdermal delivery of botulinum neurotoxin type A reduces neurogenic inflammation in the skin. Pain 149:316-324.

Covic L, Misra M, Badar J, Singh C, Kuliopulos A (2002). Pepducin-based intervention of thrombin-receptor signaling and systemic platelet activation. Nat Med 8:1161-1165. 
Curto-Reyes V, Llames S, Hidalgo A, Menendez L, Baamonde A (2010). Spinal and peripheral analgesic effects of the CB2 cannabinoid receptor agonist AM1241 in two models of bone cancer-induced pain. Br J Pharmacol 160:561-573.

Favre-Guilmard C, Auguet M, Chabrier PE (2009). Different antinociceptive effects of botulinum toxin type A in inflammatory and peripheral polyneuropathic rat models. Eur J Pharmacol 617:48-53.

Garcia-Ayllon MS, Cauli O, Silveyra MX, Rodrigo R, Candela A, Compan A, Jover R, Perez-Mateo M, Martinez S, Felipo V, Saez-Valero J (2008). Brain cholinergic impairment in liver failure. Brain 131:2946-2956.

Garcia-Martinez C, Fernandez-Carvajal A, Valenzuela B, Gomis A, Van Den Nest W, Ferroni S, Carreno C, Belmonte C, Ferrer-Montiel A (2006). Design and characterization of a noncompetitive antagonist of the transient receptor potential vanilloid subunit 1 channel with in vivo analgesic and anti-inflammatory activity. $J$ Pain 7:735-746.

Ghilardi JR, Rohrich H, Lindsay TH, Sevcik MA, Schwei MJ, Kubota K, Halvorson KG, Poblete J, Chaplan SR, Dubin AE, Carruthers NI, Swanson D, Kuskowski M, Flores CM, Julius D, Mantyh PW (2005). Selective blockade of the capsaicin receptor TRPV1 attenuates bone cancer pain. J Neurosci 25:3126-3131.

Gold MS, Gebhart GF (2010). Nociceptor sensitization in pain pathogenesis. Nat Med 16:1248-1257.

Hucho T, Levine JD (2007). Signaling pathways in sensitization: toward a nociceptor cell biology. Neuron 55:365-376.

Huster D, Vogel A, Katzka C, Scheidt HA, Binder H, Dante S, Gutberlet T, Zschornig O, Waldmann H, Arnold K. Membrane insertion of a lipidated ras peptide studied by FTIR, solid-state NMR, and neutron diffraction spectroscopy (2003). J Am Chem Soc 125:4070-4079.

Ji RR, Samad TA, Jin SX, Schmoll R, Woolf CJ (2002). p38 MAPK activation by NGF in primary sensory neurons after inflammation increases TRPV1 levels and maintains heat hyperalgesia. Neuron 36:57-68. 
Julius DA (1979). Research and development of naltrexone: a new narcotic antagonist. Am J Psychiatry 136:782-786.

Kilo S, Harding-Rose C, Hargreaves KM, Flores CM (1997). Peripheral CGRP release as a marker for neurogenic inflammation: a model system for the study of neuropeptide secretion in rat paw skin. Pain 73:201-207.

Menendez L, Lastra A, Fresno MF, Llames S, Meana A, Hidalgo A, Baamonde A (2003). Initial thermal heat hypoalgesia and delayed hyperalgesia in a murine model of bone cancer pain. Brain Res 969:102-109.

Menendez L, Lastra A, Hidalgo A, Baamonde A (2002). Unilateral hot plate test: a simple and sensitive method for detecting central and peripheral hyperalgesia in mice. $J$ Neurosci Methods 113:91-97.

Meng J, Ovsepian SV, Wang J, Pickering M, Sasse A, Aoki KR, Lawrence GW, Dolly JO (2009). Activation of TRPV1 mediates calcitonin gene-related peptide release, which excites trigeminal sensory neurons and is attenuated by a retargeted botulinum toxin with anti-nociceptive potential. J Neurosci 29:4981-4992.

Meng J, Wang J, Lawrence G, Dolly JO (2007). Synaptobrevin I mediates exocytosis of CGRP from sensory neurons and inhibition by botulinum toxins reflects their antinociceptive potential. J Cell Sci 120:2864-2874.

Mika J, Rojewska E, Makuch W, Korostynski M, Luvisetto S, Marinelli S, Pavone F, Przewlocka B (2011). The effect of botulinum neurotoxin A on sciatic nerve injuryinduced neuroimmunological changes in rat dorsal root ganglia and spinal cord. Neuroscience 175: 358-366.

Miranda P, Giraldez T, de la Pena P, Manso DG, Alonso-Ron C, Gomez-Varela D, Dominguez P, Barros F (2005). Specificity of TRH receptor coupling to G-proteins for regulation of ERG $\mathrm{K}+$ channels in GH3 rat anterior pituitary cells. J Physiol 566:717736.

Pabbidi RM, Yu SQ, Peng S, Khardori R, Pauza ME, Premkumar LS (2008). Influence of TRPV1 on diabetes-induced alterations in thermal pain sensitivity. Mol Pain 4:9. 
Polomano RC, Mannes AJ, Clark US, Bennett GJ (2001). A painful peripheral neuropathy in the rat produced by the chemotherapeutic drug, paclitaxel. Pain 94: 293304.

Premkumar LS, Qi ZH, Van BJ, Raisinghani M (2004). Enhancement of potency and efficacy of NADA by PKC-mediated phosphorylation of vanilloid receptor. $J$ Neurophysiol 91:1442-1449.

Qerama E, Fuglsang-Frederiksen A, Jensen TS (2010). The role of botulinum toxin in management of pain: an evidence-based review. Curr Opin Anaesthesiol 23:602-610.

Siau C, Xiao W, Bennett GJ (2006). Paclitaxel- and vincristine-evoked painful peripheral neuropathies: loss of epidermal innervation and activation of Langerhans cells. Exp Neurol 201:507-514.

Sprenger T, Goadsby PJ (2009). Migraine pathogenesis and state of pharmacological treatment options. BMC Med 7:71.

Suri A, Szallasi A (2008). The emerging role of TRPV1 in diabetes and obesity. Trends Pharmacol Sci 29:29-36.

Swain SM, Arezzo JC (2008). Neuropathy associated with microtubule inhibitors: diagnosis, incidence, and management. Clin Adv Hematol Oncol 6:455-467.

Torgovnick J, Arsura E, Sethi NK, Hu CJ, Yuan RY, Sheu JJ, Apfel SC (2010). Botulinum toxin for diabetic neuropathic pain: a randomized double-blind crossover trial: botulinum toxin for neuropathic pain? Neurology 74:92-93.

Van Buren JJ, Bhat S, Rotello R, Pauza ME, Premkumar LS (2005). Sensitization and translocation of TRPV1 by insulin and IGF-I. Mol Pain 1:17.

Yoon SH, Merrill RL, Choi JH, Kim ST (2010). Use of botulinum toxin type A injection for neuropathic pain after trigeminal nerve injury. Pain Med 11:630-632.

Yuan RY, Sheu JJ, Yu JM, Chen WT, Tseng IJ, Chang HH, Hu CJ (2009). Botulinum toxin for diabetic neuropathic pain: a randomized double-blind crossover trial. Neurology 72:1473-1478. 
Zhang X, Huang J, McNaughton PA (2005). NGF rapidly increases membrane expression of TRPV1 heat-gated ion channels. EMBO J 24:4211-4223.

Zhu J, Zou LP, Bakhiet M, Mix E (1998) Resistance and susceptibility to experimental autoimmune neuritis in Sprague-Dawley and Lewis rats correlate with differente levels of autoreactive T and B cell responses to myelin antigens. J. Neuosci. Res. 54: 373-381. 


\section{Footnotes}

This work was supported by grants from The Ministry of Science and Innovation [BFU2009-08346 to AF-M, SAF2007-63193 to RP-C; SAF2008-00062 to VF]; CONSOLIDER-INGENIO 2010 Program [CSD2008-00005 to AF-M, VF, PP and RPC]; la Generalitat Valenciana [Prometeo/2010/046 to AF-M and Prometeo /2009/027 to VF]; CENIT [Nanopharma to A.FM, BCN Peptides and DiverDrugs]; and Generalitat de Catalunya [FINRD 09-1-0008 to BCN Peptides, RDITSIND06-1-0676 to DiverDrugs].

Conflict of interest. AF-M is a consultant of BCN Peptides and DiverDrugs. 
JPET\#190678

\section{Legends for Figures}

Figure 1. DD04107 attenuated inflammation and hyperalgesia provoked by carrageenan and CFA. (A) Effect of DD04107 on the ipsilateral paw 4h upon intraplantar administration of carrageenan. DD04107 was administered (i.m.) at 5 $\mathrm{mg} / \mathrm{kg}$ and diclofenac at $10 \mathrm{mg} / \mathrm{kg}$ in the ipsilateral paw. (B) Area under the curve of data display in panel A. (C) Effect of DD04107 on the threshold of mechanical sensitivity of the ipsilateral paw, evaluated $5 \mathrm{~h}$ after intraplantar administration of carrageenan. DD04107 was administered at $5 \mathrm{mg} / \mathrm{kg}$ i.m. in the ipsilateral paw and the mechanical hypersensitivity followed by the Randall Selitto test. Data are given as mean \pm sem, with $n=10 . p<0.05$ using a one way analysis of variance followed by a Student-Newman.Keuls test. (D) Effect of DD04107 on the thermal hyperalgesia of the ipsilateral paw of inflamed rats taken using a plantar test. Measurements were taken 24 $\mathrm{h}$ after administration of the CFA. DD04107 was administered at $1 \mathrm{mg} / \mathrm{kg}$ i.m. in the ipsilateral paw. (E) Effect of DD04107 on the threshold of mechanical sensitivity of the ipsilateral paw, evaluated 1 and 5 days after CFA administration. DD04107 was administered at $1 \mathrm{mg} / \mathrm{kg}$ i.m. in the ipsilateral paw. (F) Mechanical sensitivity determined as percentage of response of animals evaluated using the Von Frey filaments manual "up and down" method. Measures were taken 5 days upon CFA administration and 4 days after DD04107 injection. DD04107 was administered at $1 \mathrm{mg} / \mathrm{kg}$ i.m. in the ipsilateral paw. Data for CFA model are given as mean \pm sem, with $n=8$. $p<0.05$ using the ANOVA test, followed by the Dunnett post hoc test.

Figure 2. DD04107 reduced the thermal and mechanical hypersensitivity produced by an osteosarcoma. (A) Time course of the anti-hyperalgesic effect of DD04107 on the thermal hypersensitivity produced by a tibial osteosarcoma determined using the UHP. Data are given as mean \pm sem, with $n=5 . p<0.05$ using the ANOVA test, followed by the Dunnett post hoc test. (B) Areas under the curve displayed in panel A at different peptide doses. (C) Time course of the mechanical anti-allodynic effect of DD04107 on animals bearing an osteosarcoma. Peptide was administered s.c. at $1 \mathrm{mg} / \mathrm{kg}$ (single dose). (D) Area under the curve of data display in panel C. Mechanical allodynia was determined with Von Frey filaments. Data are given as mean \pm sem, with $n=6 . p<0.05$ using the two-way ANOVA test, followed by the Bonferroni's post hoc test. 


\section{Figure 3. Effect of DD04107 on the mechanical hyperalgesia provoked by} vincristine and paclitaxel. (A) Time course of the mechanical anti-hyperalgesic effect of DD04107 in animals that developed vincristine-mediated peripheral neuropathy evaluated by the Randall Selitto test. (B) Area under the curve of data displayed in panel A. (C) Attenuation by $0.5 \mathrm{mg} / \mathrm{kg}$ DD04107 of mechanical allodynia provoked by paclitaxel-induced peripheral neuropathy determined by the Von Frey filaments. The relative anti-allodynic activity was calculated considering the maximum effect that exerted by $100 \mathrm{mg} / \mathrm{kg}$ of gabapentin (i.p.) and the minimum the mechanical allodynia displayed by animals at day 27 after administration of paclitaxel and before instillation of the peptide. (D) Area under the curve of data displayed in panel C. Peptide was administered s.c. upon detection of the peripheral neuropathies. Data are given as mean \pm sem, with $n=10 . p<0.05$ using the two-way ANOVA test, followed by the Bonferroni's post hoc test

Figure 4. DD04107 attenuates the mechanical allodynia induced by diabetic neuropathy. (A) Time course of the anti-allodynic effect of peptide DD04107 evaluated by the Von Frey Filament test. (B) Area under de curve of data displayed in panel A. Peptide was administered s.c. upon detection of the peripheral neuropathy as described in methods. Data are given as mean \pm sem, with $n \geq 9$. $p<0.05$ using the ANOVA test, followed by the Dunnett post hoc test.

Figure 5. DD04107 is a peripherally acting analgesic compound. (A) DD04107 blocks capsaicin-induced release of CGRP from primary sensory neurons in culture. Neuropeptide release was evaluated by ELISA using a specific antibody. (B) Antinociceptive activity of DD04107 is not affected by naltrexone. Naltrexone $(0.1 \mathrm{mg} / \mathrm{kg})$ was administered s.c. 30 min before the subcutaneous injection of DD04107 (5 mg/kg) and morphine $(3 \mathrm{mg} / \mathrm{kg})$. Data are given as mean \pm sem, with $\mathrm{n} \geq 12$. $\mathrm{p}<0.05$ using the Kruskal-Wallis one way analysis of variance test followed by Dunn's method.

Figure 6. Pharmacokinetic profile of DD04107. (A) PK profile of intravenous injection of $5 \mathrm{mg} / \mathrm{kg}$ of DD04107 in rats. (B) PK profile of subcutaneous administration of $10 \mathrm{mg} / \mathrm{kg}$ of DD04107 in rats. Data represent the mean of two rats. PK parameters are given in Table I. 
Figure 7. DD04107 does not affect body temperature nor thermal nociception. (A) Effect of increasing doses of DD04107 in body temperature $30 \mathrm{~min}$ and $240 \mathrm{~min}$ upon single subcutaneous administration. (B) Effect of the DD04107 in the thermal nociception at $50{ }^{\circ} \mathrm{C}$ in a hot plate, determined 30 and $240 \mathrm{~min}$ after peptide subcutaneous instillation. Data are given as mean \pm sem, with $n=4$.

Figure 8. DD04107 does not affect cardiac activity at therapeutic doses. (A) Percentage of blockade of hERG tail currents upon exposure to increasing concentrations of DD04107. hERG was expressed in HEK293 cells and the activity evaluated as described in methods. (B) Effect of increasing concentrations of DD04107 in the contractility of bathed atria in the absence (control) or presence of $300 \mathrm{nM}$ adrenaline (adrenaline). BPM denotes beats per minute. Data are given as mean \pm sem, with $n=3$. 
JPET\#190678

\section{Tables}

Table I. Pharmacokinetic parameters of compound DD04107.

\begin{tabular}{cccccccc}
\hline Route & Dose & $\mathrm{t}_{\max }$ & $\mathrm{C}_{\max }$ & $A U C_{0}^{t_{\text {last }}}$ & $\begin{array}{c}\lambda \\
\left(\mathrm{h}^{-1}\right)\end{array}$ & $\begin{array}{c}\mathrm{V}_{\mathrm{ss}} \\
(\mathrm{l})\end{array}$ & $\begin{array}{c}M R T_{0}^{t_{\text {last }}} \\
(\mathrm{h})\end{array}$ \\
\hline i.v. & 0.5 & 0 & 46.6 & 78.3 & 0.142 & 0.013 & 3.87 \\
i.v. & 5 & 0 & 461 & 184 & 0.224 & 0.020 & 2.71 \\
s.c. & 10 & 10.5 & 19.7 & 283 & 0.085 & 0.112 & 12.7 \\
\hline \hline
\end{tabular}

Values were obtained as described in methods. 
Table II. Functional observation of DD04107 effects in rats

\begin{tabular}{|c|c|c|c|c|c|c|c|c|}
\hline & \multicolumn{2}{|c|}{ Vehicle } & \multicolumn{2}{|c|}{$0.5 \mathrm{mg} / \mathrm{kg}$} & \multicolumn{2}{|c|}{$5.0 \mathrm{mg} / \mathrm{kg}$} & \multicolumn{2}{|c|}{$50 \mathrm{mg} / \mathrm{kg}$} \\
\hline & $\begin{array}{c}0.5 \\
\text { h }\end{array}$ & $4 \mathrm{~h}$ & $\begin{array}{c}0.5 \\
\text { h }\end{array}$ & $4 \mathrm{~h}$ & $\begin{array}{c}0.5 \\
\mathrm{~h}\end{array}$ & $4 \mathrm{~h}$ & $\begin{array}{c}0.5 \\
\text { h }\end{array}$ & $4 \mathrm{~h}$ \\
\hline \multicolumn{9}{|l|}{ General Parameters } \\
\hline Salivation & - & - & - & - & - & - & - & - \\
\hline Lacrimation & - & - & - & - & - & - & - & - \\
\hline Diarrhea & - & - & - & - & - & - & - & - \\
\hline Ptosis & - & - & - & - & - & - & - & - \\
\hline Tremors & - & - & - & - & - & - & - & - \\
\hline Convulsions & - & - & - & - & - & - & - & - \\
\hline Piloerection & - & - & - & - & - & - & + & - \\
\hline Straub tail & - & - & - & - & - & - & - & - \\
\hline Aggressiveness & - & - & - & - & - & - & - & - \\
\hline Stereotypes & - & - & - & - & - & - & - & - \\
\hline \multicolumn{9}{|l|}{ Specific observations } \\
\hline $\begin{array}{l}\text { Loss of olfactory } \\
\text { orientation }\end{array}$ & - & - & - & - & - & - & - & - \\
\hline Loss of hearing reflex & - & - & - & - & - & - & - & - \\
\hline $\begin{array}{l}\text { Loss of visual } \\
\text { perception }\end{array}$ & - & - & - & - & - & - & - & - \\
\hline Abdominal tone ${ }^{*}$ & $\mathrm{~N}$ & $\mathrm{~N}$ & $\mathrm{~N}$ & $\mathrm{~N}$ & $\mathrm{~N}$ & $\mathrm{~N}$ & $\mathrm{~N}$ & $\mathrm{~N}$ \\
\hline Grip strength & $\mathrm{N}$ & $\mathrm{N}$ & $\mathrm{N}$ & $\mathrm{N}$ & $\mathrm{N}$ & $\mathrm{N}$ & $\mathrm{N}$ & $\mathrm{N}$ \\
\hline Loss of rigid reflex & - & - & - & - & - & - & - & - \\
\hline Catalepsy & - & - & - & - & - & - & - & - \\
\hline Motor activity (2 min) & $\begin{array}{c}1050 \\
\pm \\
70\end{array}$ & $\begin{array}{c}900 \\
\pm \\
200\end{array}$ & $\begin{array}{c}1057 \\
\pm \\
102\end{array}$ & $\begin{array}{c}505 \\
\pm \\
223\end{array}$ & $\begin{array}{c}1131 \\
\pm \\
80\end{array}$ & $\begin{array}{c}471 \\
\pm \\
192\end{array}$ & $\begin{array}{c}1164 \\
\pm \\
55\end{array}$ & $\begin{array}{c}433 \\
\pm \\
158\end{array}$ \\
\hline Traction test $^{* *}$ & 0 & 0 & 0 & 0 & 0 & 0 & 0 & 0 \\
\hline Death $(24 \mathrm{~h})$ & 0 & 0 & 0 & 0 & 0 & 0 & 0 & 0 \\
\hline
\end{tabular}

$* \mathrm{~N}=$ normal; $* *$ Number of animals failing test after $15 \mathrm{~s}$. Number of animals tested was 4 for each condition. 
Table III. Evaluation of DD04107 on locomotor activity

\begin{tabular}{||c|c|c|c|c||}
\hline & \multicolumn{2}{|c|}{ Vehicle } & \multicolumn{2}{c||}{ 10 mg/kg DD04107 } \\
\hline & $\mathbf{1 ~ d a y}$ & $\mathbf{8}$ days & $\mathbf{1}$ day & $\mathbf{8}$ days \\
\hline Motor coordination & & & & \\
\hline Time on Rotarod & $113 \pm 16$ & $167 \pm 36$ & $110 \pm 8$ & $142 \pm 29$ \\
\hline Number of foot faults & $1.1 \pm 0.1$ & $1.8 \pm 0.3$ & $0.7 \pm 0.3$ & $2.1 \pm 0.7$ \\
\hline Time to cross the beam & $7.3 \pm 0.1$ & $6.8 \pm 0.3$ & $8.7 \pm 0.3$ & $7.2 \pm 0.7$ \\
\hline Locomotor activity & & & & \\
\hline Ambulatory count & $528 \pm 156$ & $634 \pm 177$ & $692 \pm 170$ & $722 \pm 80$ \\
\hline Ambulatory episodes & $42 \pm 12$ & $58 \pm 8$ & $61 \pm 17$ & $63 \pm 5$ \\
\hline Distance traveled & $1188 \pm 284$ & $1012 \pm 269$ & $1399 \pm 358$ & $1451 \pm 116$ \\
\hline Average velocity & $35 \pm 4$ & $33 \pm 3$ & $35 \pm 4$ & $33 \pm 2$ \\
\hline Vertical activity & & & & \\
\hline Vertical count & $199 \pm 15$ & $205 \pm 49$ & $278 \pm 49$ & $204 \pm 16$ \\
\hline Stereotypic count & $4375 \pm 415$ & $3640 \pm 426$ & $4178 \pm 474$ & $3983 \pm 147$ \\
\hline
\end{tabular}

Data are given as mean \pm sem, $n=6$. 
Table IV. Evaluation of DD04107 on learning and memory

\begin{tabular}{||c|c|c|c|c||}
\hline & \multicolumn{2}{|c|}{ VEHICLE } & 10 MG/KG DD04107 \\
\hline & 2 day & 4 days & 2day & 4 days \\
\hline Object recognition & & & & \\
\hline Exploration time (\%) & $62 \pm 3$ & -- & $62 \pm 8$ & -- \\
\hline $\begin{array}{l}\text { Spatial learning (Morris } \\
\text { water maze) }\end{array}$ & & & & \\
\hline Time to find platform (s) & $58 \pm 7$ & $27 \pm 5$ & $77 \pm 8$ & $26 \pm 5$ \\
\hline $\begin{array}{l}\text { Spatial memory* } \\
\text { Time spent in right } \\
\text { quadrant (s) }\end{array}$ & -- & $33 \pm 3$ & -- & $28 \pm 6$ \\
\hline
\end{tabular}

*Spatial memory was evaluated on day 5,i.e. $24 \mathrm{~h}$ after the learning training concluded.

Data are given as mean \pm sem, $n=6$. 


\section{Figures}


A

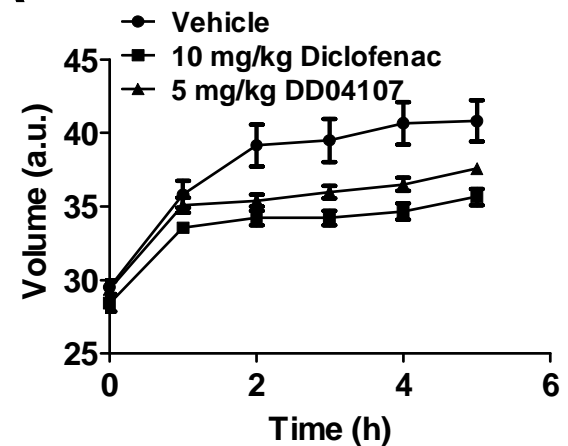

B

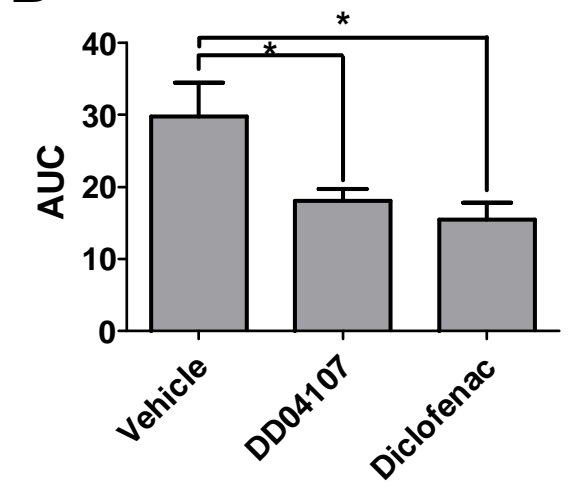

C

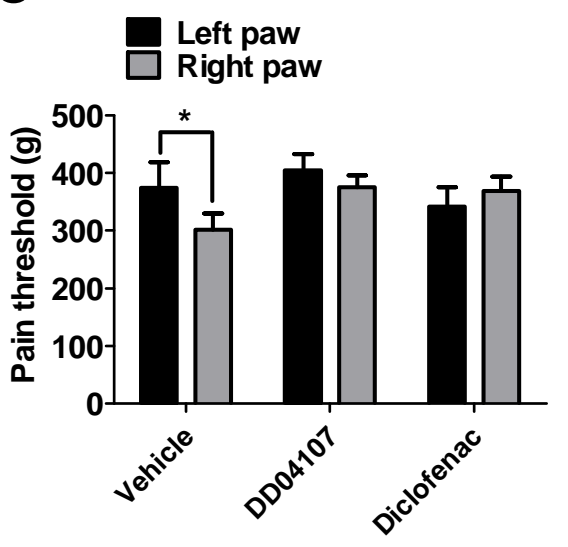

D

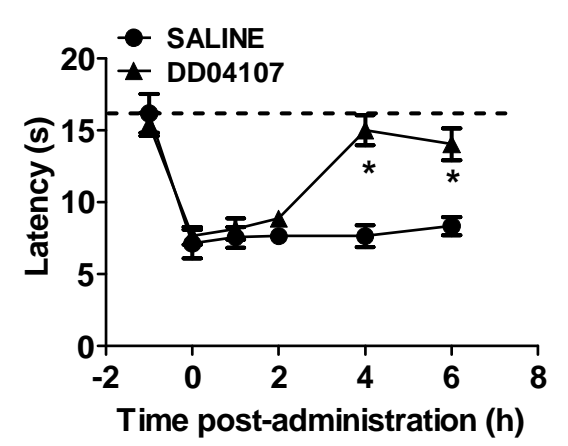

E

$\mathbf{F}$
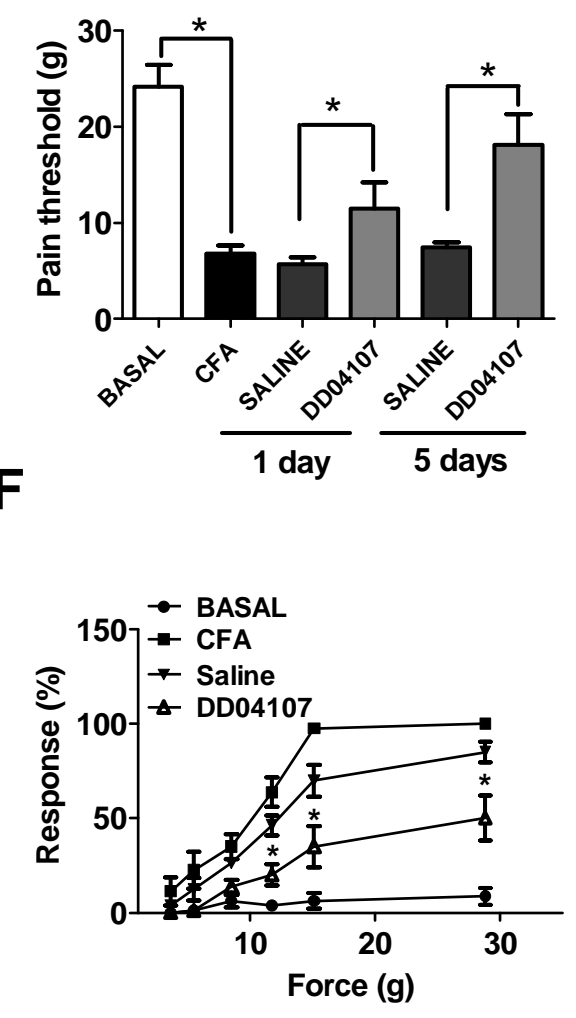

Figure 1 
A

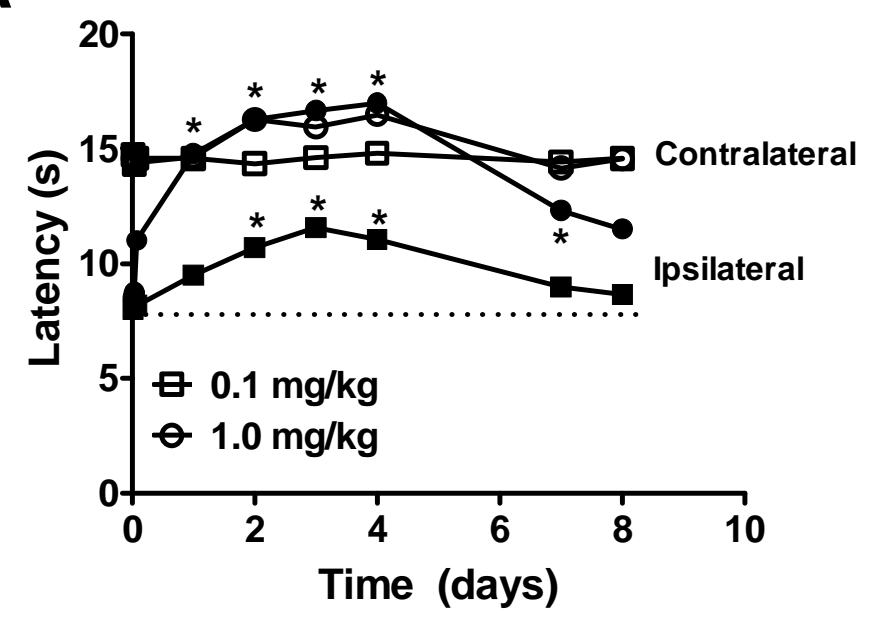

C

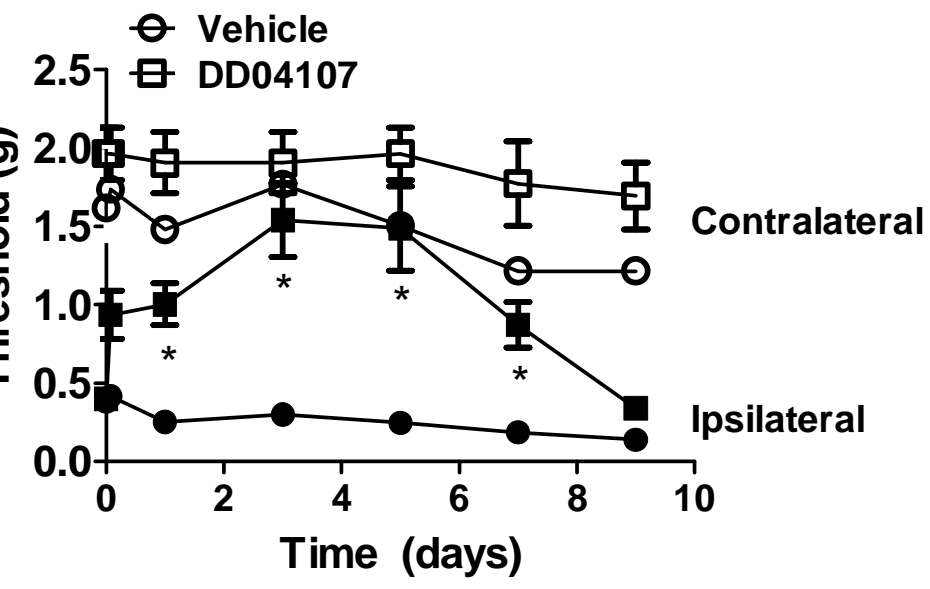

B

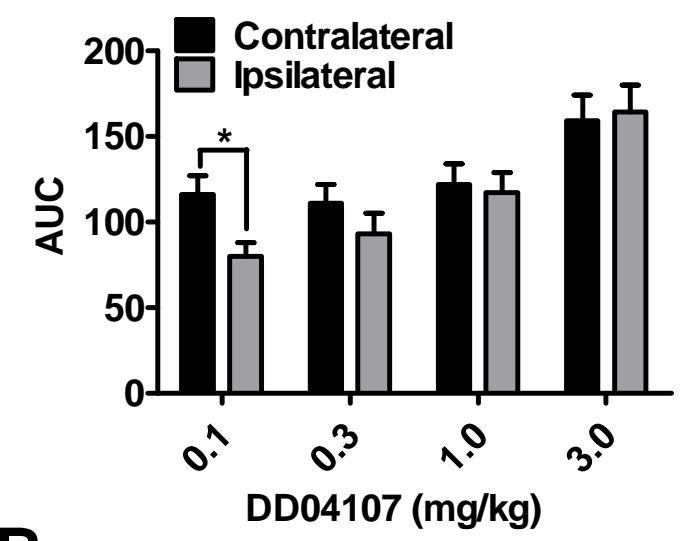

B

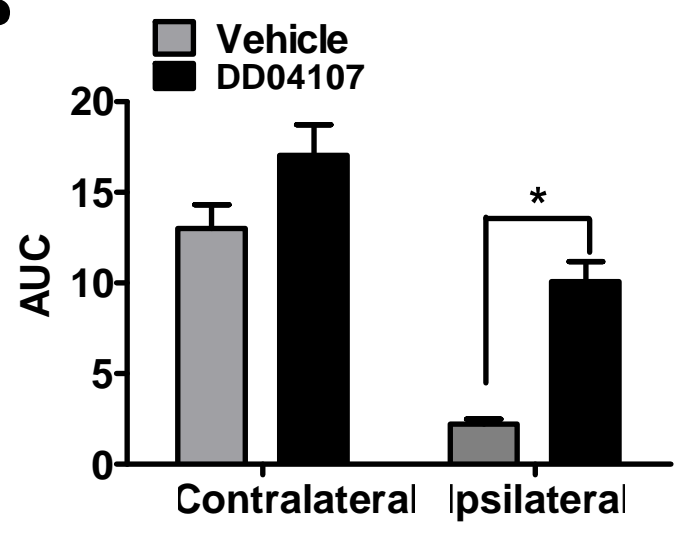

Figure 2 

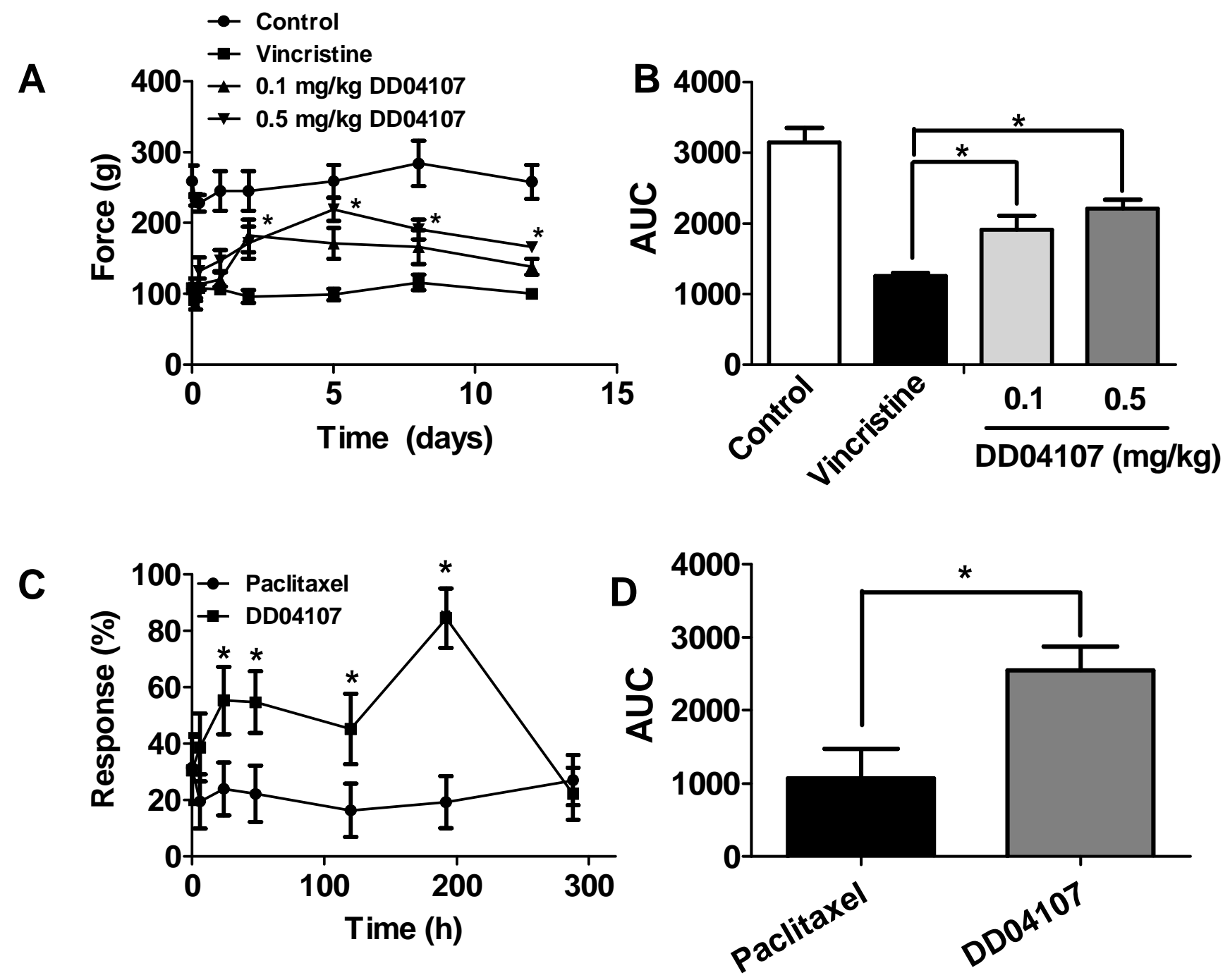

Figure 3 
A $\square$ CONTROL $\square 0.5 \mathrm{mg} / \mathrm{kg}$ DD04107

STZ 口 $5.0 \mathrm{mg} / \mathrm{kg}$ DD04107

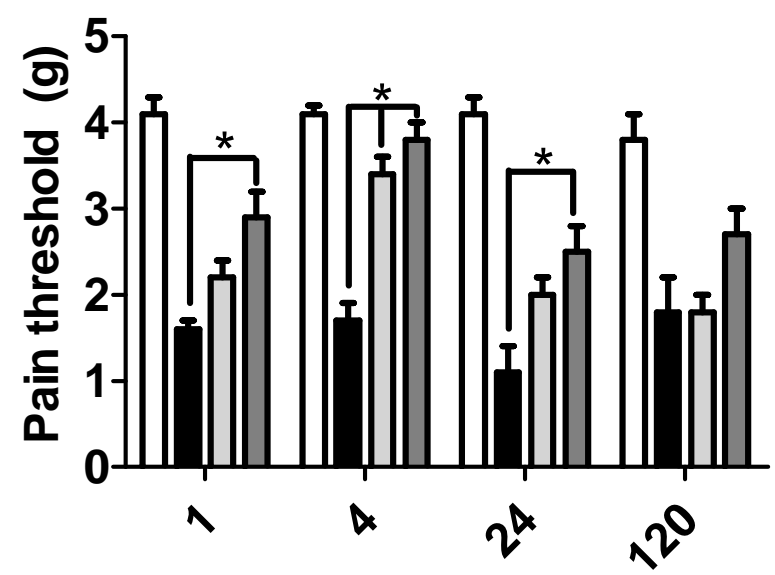

B

Time (h)

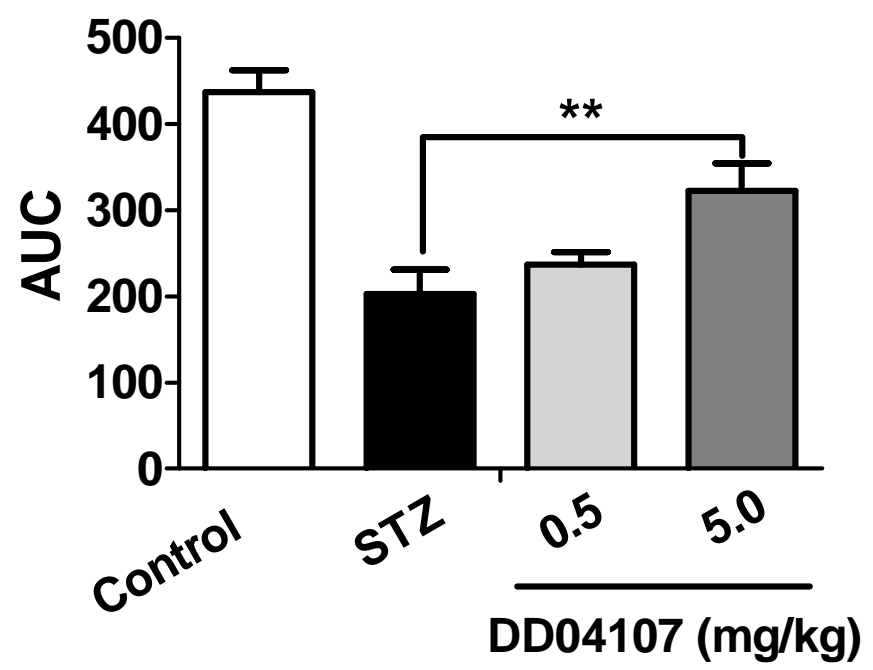

Figure 4 
A

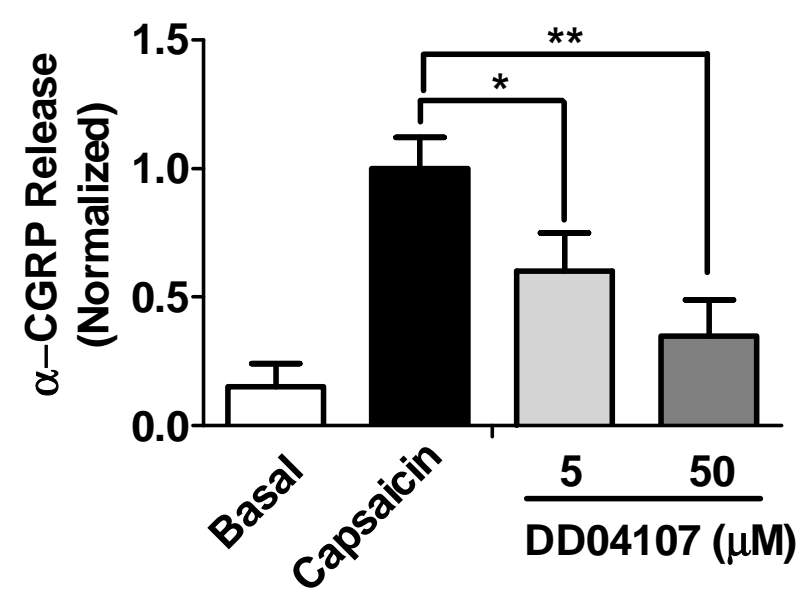

B

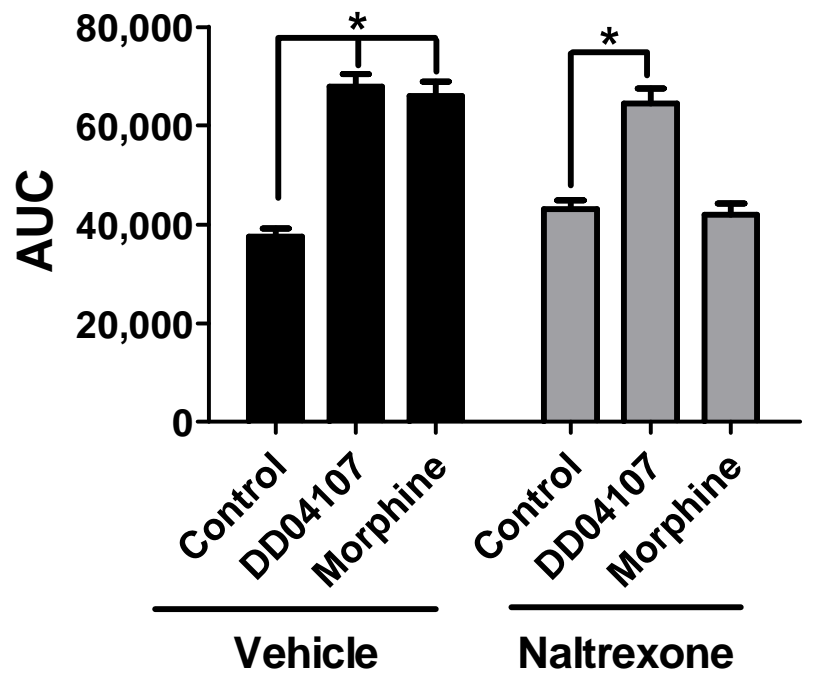

Figure 5 
A

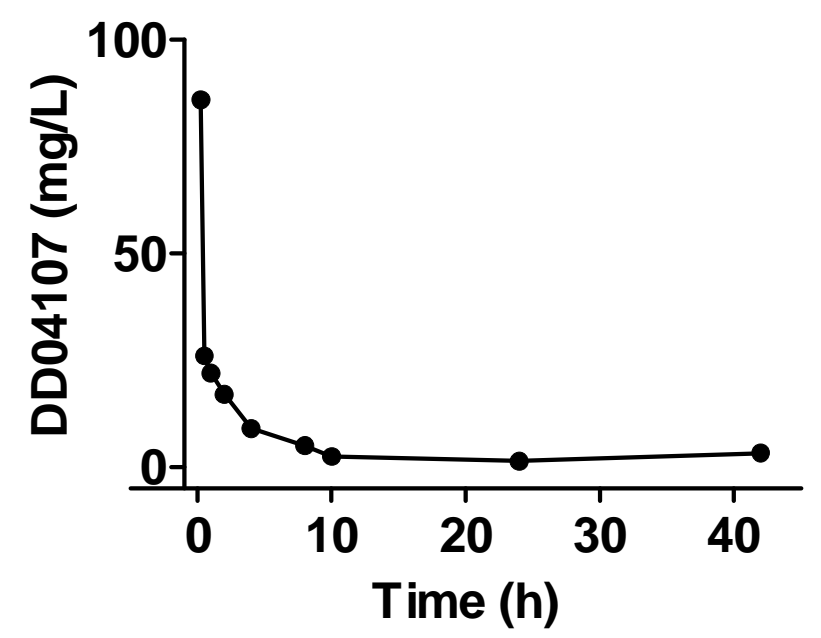

B

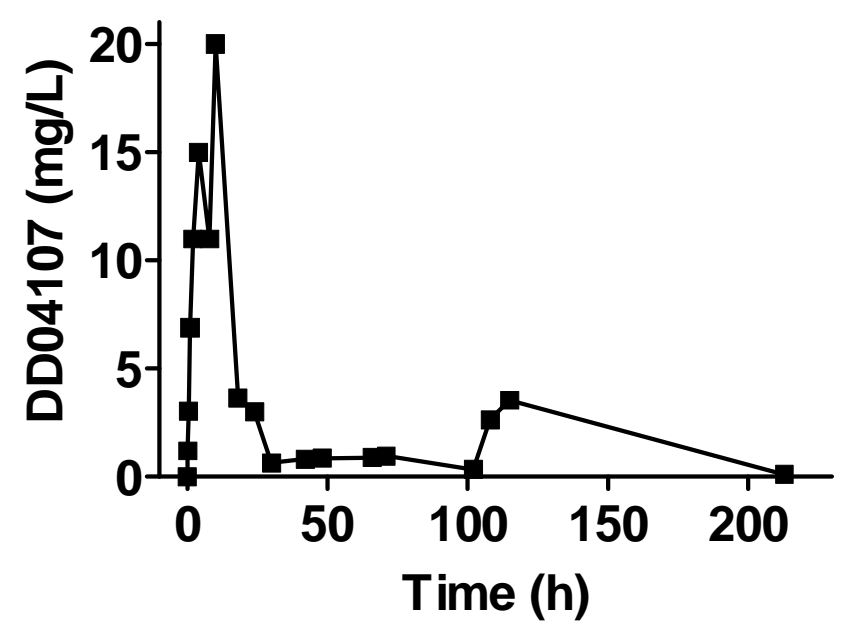

Figure 6 


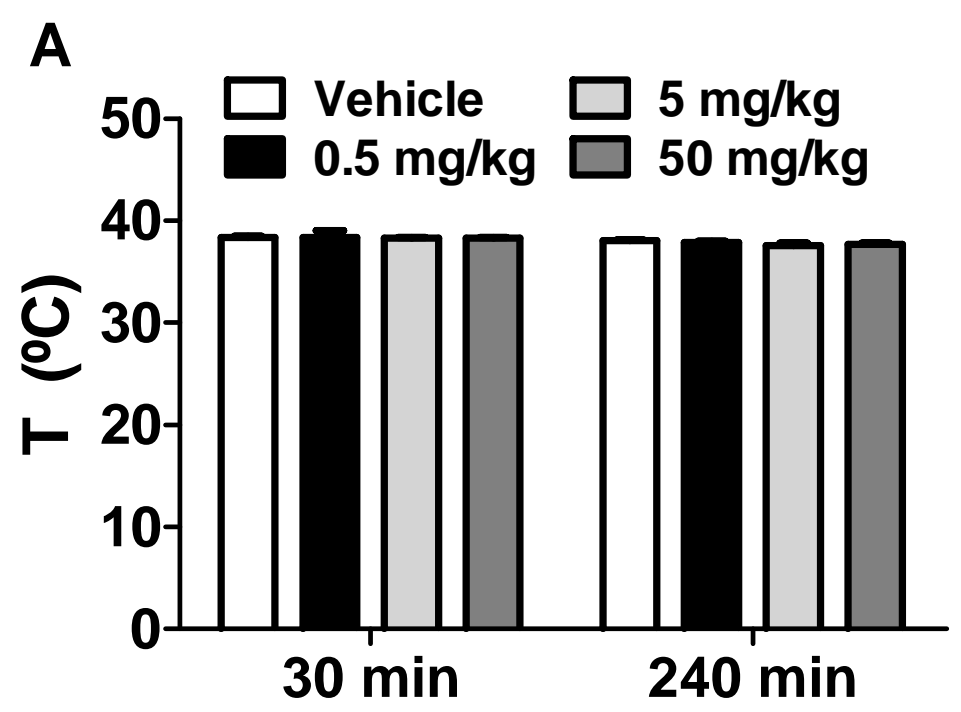

B

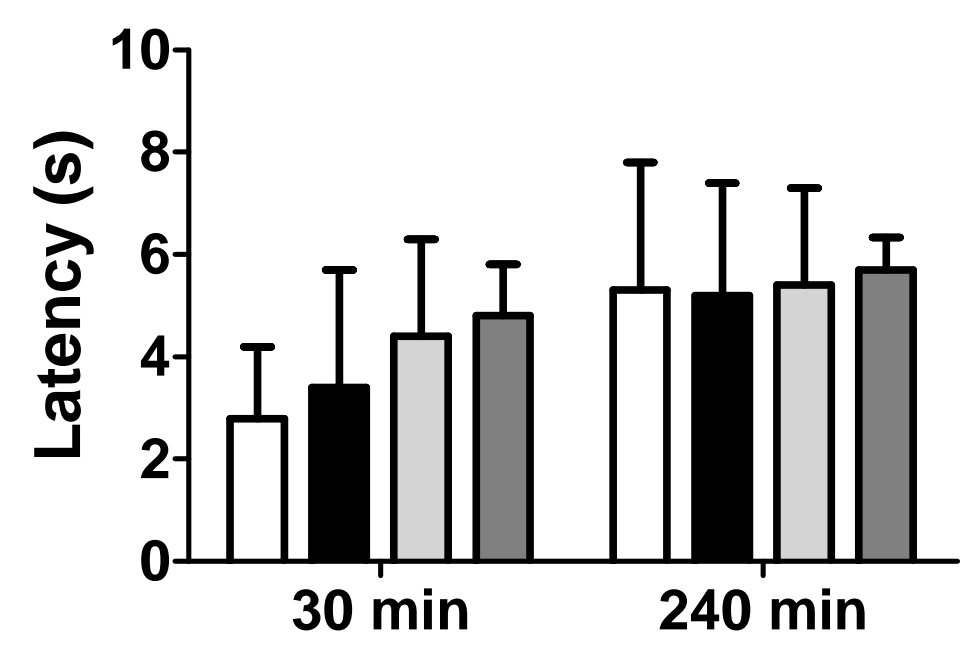

Figure 7 

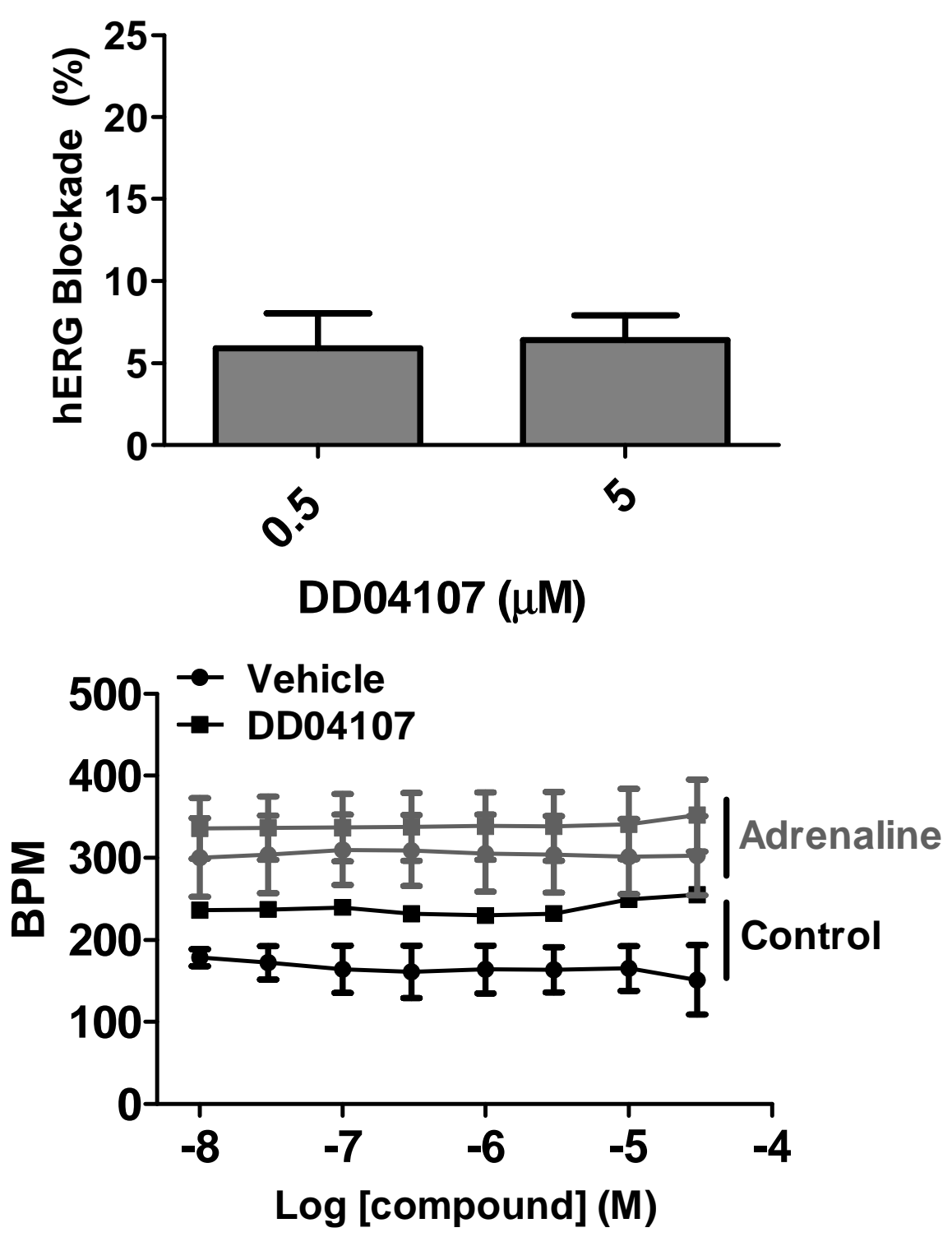

Figure 8 